\title{
Anti-Competitive Exclusion and Market Division Through Loyalty Discounts
}

\section{Citation}

Einer Elhauge \& Abraham Wickelgren, Anti-Competitive Exclusion and Market Division Through Loyalty Discounts (Harvard John M. Olin Discussion Paper Series, No. 707, Sept. (2011).

\section{Published Version}

http://www.law.harvard.edu/programs/olin_center/papers/707_Elhauge.php

\section{Permanent link}

http://nrs.harvard.edu/urn-3:HUL.InstRepos:30064393

\section{Terms of Use}

This article was downloaded from Harvard University's DASH repository, and is made available under the terms and conditions applicable to Other Posted Material, as set forth at http:// nrs.harvard.edu/urn-3:HUL.InstRepos:dash.current.terms-of-use\#LAA

\section{Share Your Story}

The Harvard community has made this article openly available.

Please share how this access benefits you. Submit a story.

\section{Accessibility}




\title{
HARVARD
}

JOHN M. OLIN CENTER FOR LAW, ECONOMICS, AND BUSINESS

\author{
ANTI-COMPETITIVE EXCLUSION \\ AND MARKET DIVISION \\ THROUGH LOYALTY DISCOUNTS
}

Einer Elhauge

Abraham L. Wickelgren

Discussion Paper No. 707

$09 / 2011$

Harvard Law School

Cambridge, MA 02138

This paper can be downloaded without charge from:

The Harvard John M. Olin Discussion Paper Series: http://www.law.harvard.edu/programs/olin_center/

The Social Science Research Network Electronic Paper Collection:

http://ssrn.com/ 


\title{
Anti-Competitive Exclusion and Market Division Through Loyalty Discounts
}

\author{
Einer Elhauge and Abraham L. Wickelgren ${ }^{1}$ \\ Harvard University and University of Texas at Austin
}

\section{September 2011}

(C2011 Einer Elhauge and Abraham L. Wickelgren. All rights reserved.

\begin{abstract}
We show that loyalty discounts create an externality among buyers even without economies of scale or downstream competition, and whether or not buyers make any commitment. Each buyer who signs a loyalty discount contract softens competition and raises prices for all buyers. We prove that, provided the entrant's cost advantage is not too large, with enough buyers, this externality implies that in any equilibrium some buyers sign loyalty discount contracts, reducing total welfare. Moreover, if loyalty discounts require buyers to commit to buy only from the incumbent, there exists an equilibrium in which all buyers sign, foreclosing the rival entirely. As a result, the incumbent can use loyalty discounts to increase its profit and decrease both buyer and total welfare.
\end{abstract}

JEL: C72, K0, K21, L12, L40, L41, L42

\footnotetext{
${ }^{1}$ Email: Elhauge@law.harvard.edu and awickelgren@law.utexas.edu. We thank the editor, Mark Armstrong, three anonymous referees, conference participants at the American Law and Economics Association Annual Meeting and the Centre for Competition Policy conference on vertical restraints, as well as seminar participants at ETH Zurich and Stanford for helpful comments. Elhauge has consulted on loyalty discount cases for both plaintiffs and defendants, with most of the cases being for plaintiffs.
} 


\section{Introduction}

The proper antitrust treatment of loyalty discounts has been a contentious issue. Some courts have held that loyalty discounts cannot be anticompetitive unless they are below cost, while other courts have rejected that proposition. ${ }^{1}$ In 2004, the Solicitor General advised the U.S. Supreme Court to avoid taking a case to resolve such legal conflicts, in part because economic analysis was too unresolved. Since then, the Supreme Court has continued not to intervene, while economic analysis on loyalty discounts has remained divided. ${ }^{2}$

Much prior analysis of loyalty discounts has focused on whether they are better treated as similar to exclusive dealing or to predatory pricing, with the focus in part turning on the extent to which certain loyalty discounts involve buyer commitments that are similar to those in ordinary exclusive dealing or instead leave the buyer free to buy elsewhere if a rival offers a lower price. Here, however, we focus on a unique feature of loyalty discounts that is not present with either ordinary exclusive dealing or ordinary predatory pricing: the fact that loyalty discounts involve a seller commitment to charge loyal buyers less than disloyal buyers. This seller commitment is a distinctive feature of loyalty discounts, and we prove here that this feature creates distinctive anticompetitive effects, with or without buyer commitments.

The seller commitment to maintain a loyalty discount reduces the seller's incentive to compete for buyers free of a loyalty agreement because lowering the price to free buyers requires lowering the price to loyal buyers who have already agreed to buy from the seller. This reduces the entrant's incentive to charge a low price, thus raising prices and harming consumer and total welfare. Buyers nonetheless agree to these contracts because of an externality. The externality is that when one buyer agrees to the loyalty discount, all buyers suffer from the higher prices that result from less aggressive competition. Thus, an incumbent supplier need not compensate an individual buyer for the losses that all other buyers suffer

\footnotetext{
${ }^{1}$ Compare, e.g., Concord Boat v. Brunswick Corp., 207 F.3d 1039, 1061-62 (8th Cir. 2000) (must be below cost), with LePage's v. 3M, 324 F.3d 141, 147-52 (3d Cir. 2003) (en banc) (need not be).

${ }^{2}$ For articles arguing that, like predatory pricing, loyalty discounts presumptively lower prices and cannot harm consumer welfare in the long run unless they are below cost, see Hovenkamp (2005); Lambert (2005); Hovenkamp (2006). For scholarship arguing that loyalty discounts can create anticompetitive effects similar to exclusive dealing, see Tom, et al., pp. 615, 623-24, 627 (2000); Elhauge, pp. $284-92$ (2003); Spector, pp. 99-101 (2005); Whinston, pp. 144-47, 166-67 (2006); Kaplow \& Shapiro, pp. 1203 n.98 \& 106 n.207 (2007); Elhauge, pp. 406-412 (2008).
} 
(whether they are covered by the loyalty discount or not). This enables an incumbent supplier to profitably induce buyers to agree to loyalty discounts that reduce overall welfare.

This seller commitment to maintain a loyalty discount is sometimes coupled with a buyer commitment to buy only (or mainly) from the seller and sometimes involves no such buyer commitment. For loyalty discounts with buyer commitment, we prove the anticompetitive effects are more robust than for ordinary exclusive dealing. In particular, we prove that, unlike ordinary exclusive dealing, loyalty discounts with buyer commitment can have anticompetitive effects even if sellers lack economies of scale, buyers are final consumers, buyers coordinate, and the contacts cover a minority of the market. Further, whereas for ordinary exclusive dealing a possible equilibrium involves all buyers rejecting anticompetitive exclusive dealing, we prove that for loyalty discounts with buyer commitment, universal buyer rejection is not a possible equilibrium if the entrant cost advantage is not too large and there are enough buyers. In any equilibrium, enough buyers will accept the loyalty discount contract to anticompetitively increase prices and reduce total welfare, and there is an equilibrium where all buyers accept, completely precluding efficient rival entry. None of these results depend on loyalty discounts being below cost; instead the effect of loyalty discounts is to increase prices even further above cost.

While we prove these results generally, we also analyze the linear demand case to get a sense of the magnitude of the problem. With linear demand, we find that whenever the incumbent can induce one buyer to sign a loyalty discount contract, all buyers sign and loyalty discounts are completely exclusionary. If there are only three buyers, loyalty discounts with buyer commitment can profitably exclude the rival from the market as long as the entrant's cost advantage is less than $10 \%$ and the incumbent's costs are less than $28 \%$ of the choke price. If there are twenty buyers, the same result can be achieved as long as the incumbent's costs are less than $80 \%$ of the choke price. In these cases, all buyers pay the incumbent's monopoly price.

We also prove that, even without any buyer commitment, as long as the entrant's cost advantage is not too large and there are at least three buyers, loyalty discounts will soften competition and increase prices above competitive levels, although they cannot completely exclude the entrant from the market. If the entrant and the incumbent choose prices simul- 
taneously or if the incumbent acts as a Stackleberg-leader, the incumbent will never cover more than half the buyers using loyalty discounts without buyer commitment and both the entrant and the incumbent will have positive market-share with positive probability. Thus, loyalty discounts without buyer commitment can also be anticompetitive even if they cover a minority of buyers. Further, these anticompetitive effects can result even if sellers lack economies of scale, buyers are final consumers, buyers coordinate, and all loyalty discounts are above cost.

The phenomenon identified here should be contrasted with price-matching or most favored nation clauses. Although such clauses also involve seller pricing commitments, they do not involve seller commitments to charge loyal buyers less than other buyers. Pricematching clauses instead involve seller commitments to match rival prices, ${ }^{3}$ whereas loyalty discounts involve no such seller commitment to match and indeed have the opposite effect of discouraging sellers from matching rival prices for free buyers. Most-favored-nations clauses involve seller commitments to charge agreeing buyers no more than the seller charges other buyers, whereas loyalty discounts involve seller commitments to charge agreeing buyers affirmatively less than the seller charges other buyers. We find that the optimal loyalty discount for the incumbent typically exceeds zero. Because the nature of the clauses differ, we find anticompetitive effects under very different conditions than are assumed in the literature on most-favored nation clauses. We find that loyalty discounts with buyer commitments can exclude entry, not just raise prices and soften competition (as happens in most-favorednations models). We also find that loyalty discounts (with or without buyer commitment) can have anticompetitive effects even in a one-shot game setting (models of most-favorednations clauses alone have found anti-competitive effects only in multi-period settings). ${ }^{4}$

\footnotetext{
${ }^{3}$ For articles arguing that, like predatory pricing, loyalty discounts presumptively lowers prices and cannot harm consumer welfare in the long run unless they are below cost, see Hovenkamp (2005); Lambert (2005); Hovenkamp (2006). For scholarship arguing that loyalty discounts can create anticompetitive effects similar to exclusive dealing, see Tom, et al., pp. 615, 623-24, 627 (2000); Elhauge, pp. 284-92 (2003); Spector, pp. 99-101 (2005); Whinston, pp. 144-47, 166-67 (2006); Kaplow \& Shapiro, pp. 1203 n.98 \& 106 n.207 (2007); Elhauge, pp. 406-412 (2008).

${ }^{4}$ Most articles on most favored nations clauses alone have found anticompetitive effects because they assumed oligopolistic coordination, see Cooper (1986), or because they assumed a monopolist selling a durable good that might use such clauses to restrain competition by itself later in time, Butz (1990); Marx \& Shaffer (2004). None of those assumptions is necessary to show anticompetitive effects from loyalty discounts under the model offered here. However, Hviid and Shaffer (2010) find that a most favored nation
} 
Our paper is related to the literature on ordinary exclusive dealing, but differs from it because that literature considers only buyer commitments to buy only (or mainly) from the seller and does not consider seller commitments to maintain a discount for loyal buyers. ${ }^{5}$ Rasmusen et al. (1991) and Segal and Whinston (2000) showed that exclusive dealing can deter entry if there are many buyers and economies of scale in production. ${ }^{6}$ Simpson \& Wickelgren (2007) extend these models to find that, even without economies of scale, sellers can still get buyers to accept an anticompetitive exclusionary agreement in exchange for a small side payment if the buyers are intermediaries. ${ }^{7}$ In contrast, they find that if buyers are instead final consumers, then buyers will breach exclusionary agreements if a breach of those agreements is enforceable only by expectation damages. Chen and Shaffer (2010) show that partially-exclusive contracts can sometimes lead to exclusion with positive probability when (in a coalition-proof equilibrium) there would be no exclusion with fully exclusive contracts.

Other papers have also analyzed contingent discounts, but they do not consider a seller commitment to maintain a loyalty discount between loyal and disloyal buyers. Ordover and Shaffer (2007) consider a model in which there is one buyer and two sellers. It is efficient for the buyer to buy one unit from each seller, but they show that with switching costs and financial constraints, the non-financially constrained firm can offer discounts on incremental units that inefficiently exclude the other firm. Marx and Shaffer (2004) show that marketshare discounts can facilitate more efficient rent-shifting between a buyer-seller pair and a second seller. As a result, if these discounts are prohibited, a buyer may have to resort to exclusively purchasing from one seller, a less efficient rent-shifting mechanism. Kolay et

clause combined with a price-matching clause can lead to elevated prices even without such assumptions.

${ }^{5}$ Also related is the vertical restraints literature that shows that vertical restraints can restrain competition even if they do not preclude entry. Rey and Stiglitz (1995) show this for exclusive territories. Lin (1990) shows this for exclusive dealing contracts that require each manufacturer to use its own retailer. Wright (2008) shows that if an upstream entrant is sufficiently differentiated from the incumbent, the incumbent will sign exclusive deals with all but one retailer to allow the entrant to enter but force its price to be high through double marginalization.

${ }^{6}$ Other articles that find exclusive dealing can have anti-competitive effects include Aghion and Bolton (1987), Mathewson and Winter (1987), Spier and Whinston (1995), Bernheim and Whinston (1998), and Neeman (1999). Innes and Sexton (1994) argue that the Chicago School claim that exclusive contracts are necessarily efficient can be resurrected if one allows all the players to form coalitions and price discrimination is prohibited.

${ }^{7}$ Argenton (2010) shows that a lower quality incumbent can deter the entry of a higher quality rival in this situation as well. For a contrary view, see Fumagalli and Motta (2006). 
al. (2004) examine the use of all-units discounts (discounts that lower the per-unit price of all units purchased when a threshold quantity is reached). They show that these discounts can arise absent any exclusionary motive because they can eliminate double marginalization with complete information and extract more profit than a two-part tariff with asymmetric information. ${ }^{8}$

Our paper is most similar to Elhauge (2009), which did analyze seller commitments to maintain loyalty discounts and found that they can have anticompetitive effects even without economies of scale. However, this paper differs from his article in several important ways that lead to different and more general results. First, his article assumes linear demand and does not allow the potential entrant to be more efficient than the incumbent seller. Our results are more general because we prove our basic results without imposing any specific functional form on buyer demand, and we allow the rival's marginal cost to be less than the incumbents. This formulation also allows us to explore, in our linear demand simulations, how much more efficient an entrant can be and still be foreclosed by loyalty discount contracts. It also allows us to investigate the optimal size of the loyalty discount, which he did not analyze.

Second, when analyzing loyalty discounts with buyer commitment, Elhauge (2009) assumes sequential rather than simultaneous pricing case when determining whether buyers will accept loyalty discount contracts. ${ }^{9}$ As a result, he finds there always exists an equilibrium in which loyalty discounts with buyer commitments have no effect because all buyers reject them. In contrast, by considering simultaneous pricing, we find that given a sufficient number of buyers (in our linear demand analysis, "sufficient" can mean three buyers),

\footnotetext{
${ }^{8}$ Our paper also shares some similarities with papers that study the interaction between financial markets and product markets. For example, Mahenc and Salanie (2004) show that sellers can commit themselves to higher prices by taking a long position in their product in the forward market. This induces their rival to also price higher, resulting in higher profits for both and lower social welfare. One can view loyalty discounts as another mechanism for committing to charging higher prices and thereby softening competition. Of course, loyalty discounts only create this commitment for part of the market, so the effect also relies on the market segmenting effect of loyalty discounts. In addition, because the commitment is sold to buyers, we must show that buyers who anticipate the effects of the loyalty discounts can still be induced to participate.

${ }^{9} \mathrm{He}$ considers simultaneous pricing (along with sequential pricing) in determining the equilibrium in the pricing subgame with a given fraction of buyers signing a loyalty discount contract, but assumes sequential pricing when analyzing whether buyers will accept the loyalty discount. When analyzing loyalty discounts with buyer commitment, we do not consider sequential pricing because our results would be nearly identical to Elhauge (2009). For loyalty discounts without buyer commitment, we do analyze sequential pricing (as well as simultaneous pricing) because our results differ from his.
} 
there does not exist an equilibrium in which all buyers reject a loyalty discount with buyer commitments.

The reason for this is that with simultaneous pricing, if the entrant enters, there is a mixed strategy pricing equilibrium. In this mixed strategy equilibrium, the incumbent's price distribution varies smoothly with the number of signers. Thus, if there is only one signer, the probability she will pay a price that exceeds the competitive price is very small if there are many buyers. Thus, the cost of inducing a buyer to sign when she believes no one else will sign is very small. The benefit to the incumbent from signing one buyer, however, must be as large under simultaneous pricing as under sequential pricing because the incumbent does charge its monopoly price with positive probability. Some of the incumbent's profit from signing up one buyer is paid by other buyers who do not sign the loyalty discount contract. This very different result is especially important given that simultaneous pricing models probably provide a much better description of reality than sequential pricing models, which is probably why simultaneous pricing is the dominant model of price interaction in economics.

Third, when analyzing loyalty discounts without buyer commitments, our analysis differs from Elhauge (2009) in several ways that changes the results. (A) He assumed that buyers will always accept discounts that do not bind them. We show that this assumption is mistaken. Because loyalty discounts affect the pricing strategy of both the incumbent and the entrant, buyers might not want to accept these discounts without compensation. By explicitly modeling buyer acceptance decisions, we are able to determine more accurately the conditions under which the incumbent can use such discount offers to elevate market prices. (B) He never formally analyzed the fraction of buyers that the incumbent would cover without economies of scale, offering instead the conjecture that it would be all but one buyer. We formally analyze the optimal fraction of buyers to whom the incumbent will offer these discounts, showing that with simultaneous pricing or if the incumbent prices first, the optimal fraction is in fact always less than half. This distinction has important policy relevance because it means that loyalty discounts without buyer commitment can, without economies of scale, have anticompetitive effects even when they cover a minority of the market. (C) Because he does not analyze the optimal fraction of buyers that will be 
covered, he does not correctly establish the prices that will be paid. We show that while loyalty discounts without commitment do enable the incumbent to steal market share from the entrant and elevate prices above the competitive level, they do not lead to monopoly pricing with probability one (contrary to Elhauge (2009)) under either simultaneous pricing or if the incumbent prices first.

Section 2 analyzes loyalty discounts with buyer commitment. In 2.1 we outline the model. In 2.2 we derive the duopoly pricing equilibrium. In 2.2.1 we derive the mixed strategy equilibrium, while 2.2.2 examines some important properties of the equilibrium. In 2.3 we consider the buyers' decisions to sign loyalty discounts with buyer commitments. Section 2.4 considers the linear demand case, with 2.4.1 examining the conditions for exclusion and 2.4 .2 analyzing the optimal loyalty discount. Section 3 considers loyalty discounts without buyer commitment, considering simultaneous pricing, entrant-first pricing, and incumbentfirst pricing. Section 4 concludes. Proofs not in the text, along with some numerical analysis, are in the appendix.

\section{Loyalty Discounts With Buyer Commitment}

\section{$2.1 \quad$ Model}

An incumbent firm, I, produces a good at constant marginal cost, c. A potential entrant, $E$, can produce this same good at marginal cost, $c_{e}<c$. We assume, to highlight the anticompetitive effects of loyalty discounts, that $E$ incurs no fixed cost to enter the market. Thus, unlike most exclusive dealing models, we do not assume economies of scale. There are $N$ buyers for the good. Each buyer's demand function is given by $q(p), q^{\prime}<0, q^{\prime \prime} \leq 0$. Let $p^{m}=\arg \max _{p}(p-c) q(p)$; that is, $p^{m}$ is I's profit-maximizing monopoly price. Let $p_{e}^{m}=\arg \max _{p}\left(p-c_{e}\right) q(p)$; that is, $p_{e}^{m}$ is $E$ 's profit-maximizing monopoly price.

Let $s(p)$ be a buyer's consumer surplus from buying $q(p)$ of the good at price $p . s(p)=$

$\int_{p}^{\infty} q(x) d x$. We make the following assumption about the maximum size of the entrant's cost advantage:

Assumption (*) $\left(p^{m}-c\right) q\left(p^{m}\right)>s\left(p_{e}^{m}\right)-s\left(p^{m}\right)$ 
Assumption $\left(^{*}\right)$ means that incumbent's profit from being a monopolist exceeds the increase in consumer surplus that results when buyers purchase at the entrant's monopoly price rather than the incumbents. Because the entrant's monopoly price depends on $c_{e}$, this simply requires that $c_{e}$ is not too far below $c$.

We have four periods in our model, which we label period 1, period 1.5, period 2, and period 3. In period 1 , the incumbent offers a loyalty discount contract to buyers of the form $\{d, t\}$ in which buyers commit to buy only from the incumbent in exchange for receiving a discount of $d$ off the price that $I$ offers to buyers who do not sign the contract and a transfer of $t$ from $I$ to the buyer. ${ }^{10}$ Buyers individually decide whether or not to accept this offer in period 1. Those who accept must buy from the incumbent in period 3 and receive the discount. Thus, for any price $p_{f}$ that the incumbent offers to free buyers who made no loyalty commitment, any buyer who did accept a loyalty commitment in period 1 receives a price of $p_{f}-d$. Notice, this means that any buyer who did not agree to a loyalty discount in period 1 will not be able to receive the discounted price from the incumbent in period 3. Let $\theta$ be the share of buyers who agree to the loyalty discount in period 1 .

In period $1.5, E$ decides whether to enter the market or not. In period $2, E$ (if active) and $I$ set prices simultaneously to free buyers of $p_{e}, p_{f}$ respectively. I's price to buyers who accept the contract is $p_{f}-d$. If $\theta=0$, then there are, in effect, no loyalty discounts. In that case, because $E$ and $I$ produce identical products, we have the standard Bertrand result that $E$ captures the entire market at a price of $p_{e}=c$. In period 3, buyers make purchase decisions.

First, suppose that $E$ enters in period 1.5 and $I$ and $E$ set prices $p_{f}$ and $p_{e}$ respectively in period 2. Then, in period 3 , if $p_{e} \leq p_{f}$, free buyers purchase only from $E$, and committed buyers purchase entirely from $I .{ }^{11}$ Thus, $I$ 's profit is $\theta\left(p_{f}-d-c\right) q\left(p_{f}-d\right)$, while $E$ 's profit

\footnotetext{
${ }^{10}$ Notice, we do not allow $I$ to commit to a price at this time. This could be because the good is hard to describe in period 1. It could be because the cost of production is not precisely known in period 1 (our model could easily accomodate a common shock to production costs). Also, as we discuss in the conclusion, committing to a price rather than a loyalty discount is not as profitable for the incumbent. Thus, agreeing to a loyalty discount simply means that the buyer receives a discount from the price (often called a "list price") offered to buyers who did not agree to a loyalty contract.

${ }^{11}$ Notice, we make the standard tie-breaking assumption that if both firms charge the identical price, then buyers buy from the lower cost firm ( $E$ in this case). This assumption makes the analysis of the standard Bertrand equilibrium less cumbersome since the equilibrium price is simply the cost of the higher cost firm
} 
is $(1-\theta)\left(p_{e}-c_{e}\right) q\left(p_{e}\right)$. If $p_{e}>p_{f}$, then all buyers purchase from $I$. Thus, I's profit is $\theta\left(p_{f}-d-c\right) q\left(p_{f}-d\right)+(1-\theta)\left(p_{f}-c\right) q\left(p_{f}\right)$ while $E$ 's profit is zero.

\subsection{Duopoly Pricing Equilibrium}

The next step is to determine the equilibrium for the period 2 pricing subgame given entry. To do so, first notice that if $\theta$ is large enough (and $d>0$ or $c_{e}<c$ ), then there is a unique pure-strategy equilibrium in which both firms charge their monopoly prices to their respective markets $\left(p_{f}=p^{m}+d\right.$ and $\left.p_{e}=p_{e}^{m}\right)$ and all committed buyers purchase from $I$ at $p^{m}$ and all free buyers purchase from $E$ at $p_{e}^{m}$. $E$ has no incentive to deviate because it is maximizing its profits. I could undercut $E$ only by charging $p_{f}=p_{e}^{m}-\varepsilon$ for some $\varepsilon>0$. If either $d>0$ or $c_{e}<c$, this implies that the price to committed buyers, $p_{f}-d<p^{m}$. For large enough $\theta$, this reduction in profits from committed buyers outweighs the gain in profits from stealing the free buyers from $E$. Thus, this is a Nash equilibrium if $\theta$ is large enough. To show that the equilibrium is unique, imagine there is another equilibrium with $p_{f} \neq p^{m}+d$. If $p_{f}>p^{m}+d$, then $I$ could easily increase its profits by reducing $p_{f}$ to $p^{m}+d$. If $p_{f}<p^{m}+d$, even if this allowed $I$ to capture the entire market, the same argument as above shows that for $\theta$ large enough, $I$ can increase its profits by setting $p_{f}=p^{m}+d$ and only selling to committed buyers. Thus, for large enough $\theta$, any equilibrium must have $p_{f}=p^{m}+d$, and E's unique best response to this is $p_{e}=p_{e}^{m}$.

To determine how large $\theta$ must be to have both firms charging their monopoly prices, notice that $I$ will only attempt to capture the entire market if it can do so at a price $p_{f}$ such that $\theta\left(p_{f}-d-c\right) q\left(p_{f}-d\right)+(1-\theta)\left(p_{f}-c\right) q\left(p_{f}\right)>\theta\left(p^{m}-c\right) q\left(p^{m}\right)$. For finite $d$, let $\bar{\theta}$ be defined implicitly by

$$
\bar{\theta}\left(p_{e}^{m}-d-c\right) q\left(p_{e}^{m}-d\right)+(1-\bar{\theta})\left(p_{e}^{m}-c\right) q\left(p_{e}^{m}\right)=\bar{\theta}\left(p^{m}-c\right) q\left(p^{m}\right)
$$

If $q\left(p_{e}^{m}-d\right)=\infty$, for large but finite $d$, then $\bar{\theta}$ will not exist. We can eliminate this problem by simply assuming that $q(p)<\infty$ for any finite $p$ (even if $p<0$ ), which would be reasonable with large and convex disposal costs. For $\theta \geq \bar{\theta}$, the argument in the last

rather than some epsilon below that level. 
paragraph establishes that there is a unique pure-strategy equilibrium in which $I$ and $E$ charge monopoly prices $\left(p^{m}\right.$ and $p_{e}^{m}$, respectively) to committed and free buyers respectively. For $\theta<\bar{\theta}$, this equilibrium does not exist because $I$ could increase its profits charging $p_{f}=p_{e}^{m}-\varepsilon$ so long as $E$ sets $p_{e}=p_{e}^{m}$.

For $\theta<\bar{\theta}$, there is no pure strategy equilibrium. To see this, define $p_{e}^{*}$ implicitly by:

$$
\left.\theta\left(p_{e}^{*}-d-c\right) q\left(p_{e}^{*}-d\right)+(1-\theta)\left(p_{e}^{*}-c\right) q p_{e}^{*}\right)=\theta\left(p^{m}-c\right) q\left(p^{m}\right)
$$

Obviously, $p_{e}^{*}$ is a function of $\theta$. For $p_{e}>p_{e}^{*}$, I's best response is to choose $p_{f}=p_{e}-\varepsilon$, while for $p_{e} \leq p_{e}^{*}$, I's best response is to choose $p_{f}=p^{m}+d$. But if $p_{f}=p_{e}-\varepsilon$, then $E$ 's best response is not to charge $p_{e}$ (because that yields zero profit), but to charge $p_{f}$ (because we have assumed that all sales go to $E$ if both charge the same price). If $p_{f}=p^{m}+d$, then $E$ 's best response is to charge $p_{e}^{m}>p_{e}^{*}$ for $\theta<\bar{\theta}$. Thus, there is no possible equilibrium in pure strategies. We have now proved the following lemma.

Lemma 1 For $\theta \geq \bar{\theta}$, the unique pure-strategy equilibrium in the period 2 pricing subgame given entry by $E$ is for $I$ to set $p_{f}=p^{m}+d$ and $E$ to set $p_{e}=p_{e}^{m}$. Then $I$ sells to committed buyers at $p^{m}$ and $E$ sells to free buyers at $p_{e}^{m}$. For $\theta<\bar{\theta}$, there is no pure-strategy equilibrium in the period 2 subgame if $E$ has entered.

Thus, if the fraction of buyers who have committed to buy from the incumbent is large, then the market will be effectively divided, and all buyers will face only one seller and pay monopoly prices. Of course, because $\bar{\theta}$ depends on $d$, the incumbent can influence how many buyers it takes to create this pure strategy equilibrium. The larger is the discount $d$, the smaller is the minimum fraction of buyers $\bar{\theta}$ that is needed to generate the monopoly pricing equilibrium. That said, as we will see below, a very large $d$ also makes it more costly to induce buyers to sign a loyalty discount contract if they believe other buyers will not do so. For example, for large enough $d$, one buyer signing could create the monopoly pricing equilibrium. If that is the case, then it would be impossible to eliminate an equilibrium in which no buyer signs the loyalty discount contract because each buyer would require its lost consumer surplus from paying the monopoly price rather than the competitive price, which would be more than the incumbent's profit. As we will see below, however, if $d$ is 
small enough, given the number of buyers who accept the loyalty commitment, then there is no pure strategy equilibrium. In the next section, we derive a mixed strategy pricing equilibrium for this case. Given this mixed strategy equilibrium, we show that there cannot exist an equilibrium of the entire game in which no buyer signs the loyalty discount contract.

\subsubsection{Deriving the Mixed Strategy Equilibrium}

The next step is the characterize the mixed strategy equilibrium that exists for $\theta<\bar{\theta}$. Let $F(p)$ denote the cumulative distribution function of the incumbent's price to free buyers and let $f$ be the associated probability density function. Let $F_{e}(p)$ denote the cumulative distribution function of the entrant's price with associated density function $f_{e}$. The incumbent's flow profit (ignoring any transfers from loyalty contracts) from a price of $p_{f}$ to free buyers is:

$$
\theta\left(p_{f}-d-c\right) q\left(p_{f}-d\right)+(1-\theta)\left(1-F_{e}\left(p_{f}\right)\right)\left(p_{f}-c\right) q\left(p_{f}\right)
$$

The incumbent sells to all committed buyers at a price of $p_{f}-d$. It also sells to the $1-\theta$ free buyers if the entrant's price is greater than $p_{f}$. This occurs with probability $1-F_{e}\left(p_{f}\right)$.

For the incumbent to play a mixed strategy, it must be that its profit is the same for all prices in the support of $f$. This implies that (3) must be the same for all $p_{f}$. The following lemma provides a condition on this profit function to enable us to solve for $F_{e}$.

Lemma 2 In any mixed strategy equilibrium, I chooses $p_{f}=p^{m}+d$ with positive probability.

Proof. Because $E$ will never charge above $p_{e}^{m}$, we know that $I$ will never choose $p_{f} \in\left[p_{e}^{m}\right.$, $\left.p^{m}+d\right)$, because this would result in $I$ making zero sales to uncommitted buyers and a price to committed buyers that is less than the $p^{m}$ that would maximize profits if $I$ makes no uncommitted sales. That is, if $I$ ever charges a price to free buyers at or above $p_{e}^{m}$, that price must be $p^{m}+d$. Thus, if $I$ never charges $p^{m}+d$, then $I$ always prices strictly below $p_{e}^{m}$. $E$ 's maximum price must never exceed $I$ 's maximum price because $E$ would have zero profit if it charged such a price. But, if I's maximum price to free buyers exceeds E's maximum price, then $I$ will have no sales to uncommitted buyers, in which case it is better off charging $p^{m}+d$. Q.E.D. 
If $I$ chooses $p^{m}+d$ with positive probability, its profits from any price it chooses must be $\theta\left(p^{m}-c\right) q\left(p^{m}\right)$. Using this condition, we can use $(3)$ to solve for $F_{e}$ :

$$
F_{e}(p)=1-\theta \frac{\left(p^{m}-c\right) q\left(p^{m}\right)-(p-d-c) q(p-d)}{(1-\theta)(p-c) q(p)}
$$

Notice, however, that using (4), the entrant's distribution function doesn't become one until a price of $p^{m}+d$. But, $E$ has no reason to ever charge above $p_{e}^{m}$. Thus, there is an atom in the entrant's pricing distribution at $p_{e}^{m}$ of $\theta \frac{\left(p^{m}-c\right) q\left(p^{m}\right)-\left(p_{e}^{m}-d-c\right) q\left(p_{e}^{m}-d\right)}{(1-\theta)\left(p_{e}^{m}-c\right) q\left(p_{e}^{m}\right)}$. We will denote the bottom of the support of the entrant's pricing distriubtion by $p_{0}$, which is defined implicitly by

$$
\theta\left(p_{0}-d-c\right) q\left(p_{0}-d\right)+(1-\theta)\left(p_{0}-c\right) q\left(p_{0}\right)=\theta\left(p^{m}-c\right) q\left(p^{m}\right)
$$

By using (5) in (4), one can see that $F_{e}\left(p_{0}\right)=0$. Thus, the entrant's pricing distriubtion has support of $\left[p_{0}, p_{e}^{m}\right]^{12}$ and, abusing notation slightly, we write the entrant's pricing distribution function as:

$$
F_{e}(p)= \begin{cases}1-\theta \frac{\left(p^{m}-c\right) q\left(p^{m}\right)-(p-d-c) q(p-d)}{(1-\theta)(p-c) q(p)} & \text { for } 0 \leq p<p_{e}^{m} \\ 1 & \text { for } p \geq p_{e}^{m}\end{cases}
$$

To determine the incumbent's pricing distribution function, we look at the entrant's profit from charging a price of $p_{e}$ :

$$
(1-\theta)\left(1-F\left(p_{e}\right)\right)\left(p_{e}-c_{e}\right) q\left(p_{e}\right)
$$

The entrant only sells to the $1-\theta$ buyers who have not committed to buy from the incumbent and receive the loyalty discount. It only sells to those buyers if the incumbent's price to free buyers is higher than the entrant's price. This occurs with probability $1-F\left(p_{e}\right)$. For the entrant to play a mixed strategy, it must receive the same profits for all prices in the support of $F_{e}$. Notice that there is a minimum price in I's distribution is also given by $p_{0} . \quad p_{0}$ is price for which $I$ earns as much profit from capturing the entire market at a price (and charging free buyers $p_{0}$ and committed buyers $p_{0}-d$ ) as it would from only selling to

\footnotetext{
${ }^{12} p_{0}<p_{e}^{m}$ is guaranteed by $\theta<\bar{\theta}$.
} 
committed buyers at the monopoly price. I certainly would never charge less than $p_{0}$ to free buyers. The minimum of its pricing support cannot exceed this level because if it did, then $E$ would price above $p_{0}$ with probability one. In that case, $I$ could increase its profits by charging free buyers just under $E$ 's minimum price but above $p_{0}$ because then it would capture the entire market while charging free buyers greater than $p_{0}$. Using (5) and (7), we can solve for $F$ :

$$
F(p)=1-\frac{\left(p_{0}-c_{e}\right) q\left(p_{0}\right)}{\left(p-c_{e}\right) q(p)}
$$

Once again, notice that using (8), I has a positive probability of choosing a price to free buyers that exceeds $p_{e}^{m}$. We know that the only price above $p_{e}^{m}$ that $I$ ever charges is $p^{m}+d$. Thus, there is an atom at $p^{m}+d$ of $\frac{\left(p_{0}-c_{e}\right) q\left(p_{0}\right)}{\left(p_{e}^{m}-c_{e}\right) q\left(p_{e}^{m}\right)}$, so that the actual distribution function for I's price to free buyers has support of $\left[p_{0}, p_{e}^{m}\right] \cup p^{m}+d$ and is given by:

$$
F(p)=\left\{\begin{array}{c}
1-\frac{\left(p_{0}-c_{e}\right) q\left(p_{0}\right)}{\left(p-c_{e}\right) q(p)} \text { for } 0 \leq p<p_{e}^{m} \\
1-\frac{\left(p_{0}-c_{e}\right) q\left(p_{0}\right)}{\left(p_{e}^{m}-c_{e}\right) q\left(p_{e}^{m}\right)} \text { for } p \in\left[p_{e}^{m}, p^{m}+d\right) \\
1 \quad \text { for } p \geq p^{m}+d
\end{array}\right.
$$

\subsubsection{Properties of the Mixed Strategy Equilibrium}

Given the fraction of buyers, $\theta$, who sign the loyalty discount contract and the magnitude of the discount, $d$, the pricing equilibrium is given by equations (6) and (9). Using these equations, we can derive the effect of the entrant's and incumbent's costs, the fraction of signers, and the magnitude of the discount on the pricing equilibrium. The first proposition does that.

Proposition 1 If $p_{e}^{m}$ satisfies Assumption (*), for any fixed $\theta \in(0, \bar{\theta}), d>0$ and $c_{e}<c$ :

(i) An increase in $c_{e}$ to $c_{e}^{\prime}$ has no affect on the entrant's pricing distribution below $p_{e}^{m}$ but creates a positive probability of prices $p_{e} \in\left(p_{e}^{m}, p_{e}^{\prime m}\right]$. An increase in $c_{e}$ to $c_{e}^{\prime}$ increases the probability that the incumbent chooses a price lower than any given level $p<p_{e}^{m}$ but creates a positive probability of prices $p \in\left(p_{e}^{m}, p_{e}^{\prime m}\right]$. (ii) An increase in $c$ reduces the probability that both the entrant and the incumbent choose a price lower than any given level $p<p_{e}^{m}$. (iii) An increase in $\theta$ reduces the probability that both 
the entrant and the incumbent choose a price lower than any given level $p<p_{e}^{m}$. (iv) An increase in d reduces the probability that both the entrant and the incumbent choose a price lower than any given level $p<p_{e}^{m}$.

Proof. See Appendix.

Because we have a mixed strategy equilibrium in which the entrant's price distribution is such that the incumbent is indifferent between a range of prices, changes in the entrant's costs within the relevant range (below the incumbent's cost but still satisfying Assumption $(*)$ ) do not affect its pricing distribution because they do not directly affect the incumbent's profit. Increasing the entrant's costs within this range, however, does make the incumbent price more aggressively. This is necessary to ensure that the higher cost entrant does not strictly prefer prices at the high end of its distribution. The effect of increasing the incumbent's cost is very different because the incumbent has the option of selling to its captive buyers at its monopoly price. Thus, the entrant's price distribution must be such that the incumbent is indifferent between ceding the free buyers to the entrant and competing for them. When the incumbent's cost increase, it becomes less profitable for it to compete for free buyers at a given distribution of entrant prices, thus, the entrant must price less aggressively to maintain the incumbent's mixed strategy. The incumbent's minimum profitable price to sell to free buyers increases with its costs, and this makes its entire price distribution less aggressive. Not surprisingly, increasing the share of captive buyers makes the incumbent less aggressive in capturing free buyers, and this, in turn, makes the entrant less aggressive as well. A larger discount has the same effect because it makes it more costly for the incumbent to compete for free buyers by reducing its profit from captive buyers. Thus, large discounts can make it more expensive to induce buyers to sign the loyalty discount contract. When considering the effect of costs on pricing, it is also important to note that this takes as given the period 1 loyalty discount decisions. Because, for example, higher entrant costs make the incumbent price more aggressively, that should make signing the loyalty discount contract more attractive. We turn next to the decision to sign or reject loyalty discount contracts. 


\subsection{Buyer Loyalty Discount Decisions}

Now that we have established the distribution of prices buyers will face given entry, we can determine buyer's optimal decisions regarding acceptance of the incumbent's loyalty discount offers. Proposition 2 gives our main result for loyalty discounts with commitment.

Proposition 2 (A) If $N$, the number of buyers, is sufficiently large and $c-c_{E}$ is small enough, then there exists $a d \geq 0$ and $t \geq 0$ for which the incumbent can profitably offer buyers a loyalty discount contract of $\{d, t\}$ such that, in any equilibrium in the subgame following this offer, some buyers accept this offer and prices exceed what they would have been absent loyalty discounts.

(B) There exists an $\bar{N}_{B}$ such that if the number of buyers exceeds $\bar{N}_{B}$ and the entrant's cost advantage is not too large (i.e., Assumption (*) holds), then there exists a $d \geq 0$ and $t \geq 0$ for which the incumbent can profitably offer buyers a loyalty discount contract of $\{d, t\}$ such that there exists a subgame perfect equilibrium in which all buyers accept the incumbent's offer, the entrant does not enter, and all buyers purchase from the incumbent at $p^{m}$.

Proof. First, we prove Proposition 2(B), that there exists an equilibrium in which all buyer's accept a loyalty discount contract that increases the incumbent's profit. A buyer's payoff from accepting a loyalty discount contract depends on its expectations about what other buyers will do. If it expects that, even after rejecting this contract, $\theta \geq \bar{\theta}$, then it will pay $p^{m}$ if it accepts the contract and $p_{e}^{m}$ if it rejects. Because we have assumed that $\left(p^{m}-c\right) q\left(p^{m}\right)>s\left(p_{e}^{m}\right)-s\left(p^{m}\right)$, there exists a $t \in\left(\left[s\left(p_{e}^{m}\right)-s\left(p^{m}\right),\left(p^{m}-c\right) q\left(p^{m}\right)\right]\right.$ such that all buyers will accept $\{d, t\}$ for such a $t$ (and any $d \geq 0$ ) if they believe enough other buyers will (such that $\theta \geq \bar{\theta}$ even if they reject). Because all buyers accept the contract, the incumbent can profitably offer this contract with $t \leq\left(p^{m}-c\right) q\left(p^{m}\right)$. As long as either $d>0$ or $c_{E}<c$, $\bar{\theta}<1$. This means that for sufficiently large $N,(N-1) / N>\bar{\theta}$. Thus, there will be an equilibrium in which all buyers accept this loyalty discount contract. Because all buyers accept, the entrant cannot profitably enter and the incumbent will charge all buyers $p^{m}$.

Next, we prove Proposition 2(A). That is, we show that the incumbent can profitably guarantee that there does not exist an equilibrium in which all buyers reject the loyalty 
discount contract. To do so, first notice that if all buyers reject the loyalty discount contract, then each buyer can purchase the good at $c$, the incumbent's cost, and obtain surplus of $s(c)$. If $N-1$ buyers reject the loyalty discount contract, then the one remaining buyer can, if it signs the loyalty discount contract, purchase the good from only the incumbent at $p_{f}-d$. Thus, this buyer's surplus from accepting depends on the distribution of the incumbent's price to free buyers, $p_{f}$, when $N-1$ buyers are not committed. This distribution depends on the number of committed buyers because $p_{0}$, determined by equation (5), is a function of $\theta$. Notice that as $\theta \rightarrow 0, p_{0} \rightarrow c$. Thus, by making $N$ large enough, we can make $p_{0}$ arbitrarily close to $c$.

Equation (9) tells us that the probability that $I$ charges a price to free buyers above $p$ is $\frac{\left(p_{0}-c_{e}\right) q\left(p_{0}\right)}{\left(p-c_{e}\right) q(p)}$ (as long as $\left.p<p_{e}^{m}\right)$. Because we can make $p_{0}$ arbitrarily close to $c$, this probability will be arbitrarily close to zero for $p>c$ if $c_{e}=c$. That is, if the entrant has no cost advantage, as $N$ gets very large, the incumbent will charge a price arbitrarily close to $c$ with probability arbitrarily close to one. This means that even if $d=0$, the committed buyer will obtain a consumer surplus of arbitrarily close to $s(c)$, the same surplus she would obtain if she were free. Thus, if $c_{E}=c$, if a buyer thinks all other buyers will not sign, this buyer can be induced to sign a loyalty discount contract for an arbitrarily small amount. Recall, however, from the construction of the mixed strategy equilibrium, that the incumbent's expected profit from having this buyer sign the loyalty discount contract is still $\left(p^{m}-c\right) q\left(p^{m}\right)>>0$. Furthermore, because $F$ is continuous in $c_{E}$, for $c-c_{E}$ small enough, the buyer's expected surplus loss from signing the loyalty discount contract will remain less than $\left(p^{m}-c\right) q\left(p^{m}\right)$. Thus, as long as $c-c_{E}$ is small enough, the incumbent will always offer a payment large enough to induce one buyer to sign the loyalty discount contract. Hence, there will never be an equilibrium in which all buyers are free. As long as some buyers are committed, equations (9) and (6) indicate that prices will exceed $c$ with positive probability. Q.E.D.

Proposition 2 says that if the incumbent can offer loyalty discounts, then if the entrant's cost advantage is not too large and there are many buyers, there will never be an equilibrium in which all buyers reject these loyalty discounts. This occurs even though these loyalty discounts raise prices above the competitive level and make all buyers worse off. While prior 
results (Rasmusen et al. 1991, Segal and Whinston 2000) on basic exclusive dealing contracts have established that these contracts can create an equilibrium in which all buyers also sign exclusive dealing contracts and buyers pay supra-competitive prices as a result, Proposition 2 demonstrates that loyalty discount contracts are more damaging for two reasons. First, with basic exclusive dealing contracts, when buyers are offered exclusive contracts simultaneously, there is always an equilibrium in which every buyer rejects the contract and all buyers pay competitive prices. In fact, this is the unique perfectly coalition proof Nash equilibrium. In contrast, Proposition 2 shows that with loyalty discount contracts, such an equilibrium does not always exist. With enough buyers, if the incumbent's costs are not too far above the entrants, then some buyers must always sign the loyalty discount contracts because the expected increase in price to the signing buyer is very small if very few buyers sign, so the cost to compensate this buyer is less than the added profit from having one more committed buyer (which is the monopoly profit from serving this buyer). This results in all buyers paying supra-competitive prices (even if buyers can form coalitions). Second, the prior results on exclusive dealing, at least when buyers are final consumers or independent monopolists, only demonstrated anticompetitive results in the presence of economies of scale. Proposition 2 shows that loyalty discounts will have anticompetitive results even with constant returns to scale.

The reason that loyalty discounts have such robust anticompetitive effects is that they create a negative externality among buyers even without economies of scale. Every buyer who signs a loyalty discount contract changes both the incumbent's and the entrant's pricing distributions by making them less aggressive. The more buyers who are committed to buy from the incumbent, the more attractive it is for the incumbent simply to exploit those buyers, which makes it less aggressive in trying to lower its price to attract free buyers. This, in turn, makes the entrant less aggressive in attracting free buyers. Thus, a buyer who signs a loyalty discount contract passes some of the social loss from doing so onto other buyers. This makes it possible to induce buyers to sign even though there is dead weight loss associated with these contracts.

Once enough buyers are expected to sign these contracts, the market is effectively divided: the incumbent only competes for committed buyers and the entrant only competes for free 
buyers. In this case, as long as the entrant's cost advantage is small enough to satisfy Assumption $\left(^{*}\right)$, the incumbent can always compensate buyers enough so that all will sign the contract. Thus, there is always an equilibrium in which all buyers sign the loyalty discount contracts. If fewer buyers are expected to sign, there may be greater losses for buyers from being committed to buy from the incumbent. However, Proposition 1 shows that, at least for the first buyer who signs the loyalty discount contract, this loss may still be less than the incumbent's profit. It is possible, however, that there could be an intermediate equilibrium in which some number of buyers between one and $N$ sign the loyalty discount contract. This would not result in complete exclusion, but it does lead to prices that are above the competitive level with positive probability. Proposition 1 does not rule out this possibility, but we have not found any cases in which loyalty discounts with commitment result in only partial exclusion. As we show in the next subsection, in the case of linear demand, if the entrant's cost advantage is small enough then the equilibrium in which all buyers sign the loyalty discount contracts is unique. In section 3, however, we do find partial exclusion in the case of loyalty discounts without commitment.

Proposition 2 says that anticompetitive effects are guaranteed if there are enough buyers and the entrant's cost advantage is small enough. Even with a general demand function, we can go further to say that the effect of the entrant's cost and the number of buyers on the ability of the incumbent to get one signer is monotonic. Proposition 3 describes the result.

Proposition 3 (i) If, for any given $c$ and $N$, the incumbent can profitably induce at least one buyer to sign a loyalty discount contract in period 1 if the entrant's costs are $\bar{c}_{e}$, then the incumbent can induce at least one buyer to sign a loyalty discount contract in period 1 if the entrant's costs are $c_{e}>\bar{c}_{e}$. (ii) If, for any given $c$ and $c_{e}$, the incumbent can profitably induce at least one buyer to sign a loyalty discount contract in period 1 if the there are $\bar{N}$ buyers, then the incumbent can induce at least one buyer to sign a loyalty discount contract in period 1 if there are $N>\bar{N}$ buyers.

Proof. If all buyers reject the loyalty discount contract, then all buyers buy at $c$. If one buyer accepts the loyalty discount contract, then it pays a price of $p-d$ where $p$ is distributed according to (9). The consumer surplus associated with any given price is 
clearly decreasing in price. (i) Expected consumer surplus from signing a loyalty discount contract is $\int_{p_{0}}^{p_{e}^{m}} s(p-d) f(p) d p+\frac{\left(p_{0}-c_{e}\right) q\left(p_{0}\right)}{\left(p_{e}^{m}-c_{e}\right) q\left(p_{e}^{m}\right)} s\left(p^{m}\right)$. Differentiating this with respect to $c_{e}$ (and realizing that $p_{e}^{m}$ depends on $c_{e}$ ) gives the following:

$$
\int_{p_{0}}^{p_{e}^{m}} s(p-d) \frac{d f(p)}{d c_{e}} d p+f\left(p_{e}^{m}\right) s\left(p_{e}^{m}-d\right) \frac{d p_{e}^{m}}{d c_{e}}-\frac{\left(p_{e}^{m}-p_{0}\right) q\left(p_{0}\right)}{\left(p_{e}^{m}-c_{e}\right)^{2} q\left(p_{e}^{m}\right)} s\left(p^{m}\right)
$$

The last term does not contain a $\frac{d p_{e}^{m}}{d c_{e}}$ term because the term multiplying it is zero by the envelope theorem. Differentiating (8) with respect to $p$ and evaluating at $p_{e}^{m}$ gives $f\left(p_{e}^{m}\right)=\frac{\left(p_{0}-c_{e}\right) q\left(p_{0}\right)\left(q\left(p_{e}^{m}\right)+\left(p_{e}^{m}-c_{e}\right) q^{\prime}\left(p_{e}^{m}\right)\right)}{\left(p_{e}^{m}-c_{e}\right)^{2} q\left(p_{e}^{m}\right)^{2}}=0$ because $q\left(p_{e}^{m}\right)+\left(p_{e}^{m}-c_{e}\right) q^{\prime}\left(p_{e}^{m}\right)=0$ by definition of $p_{e}^{m}$. Because surplus is decreasing in price, the first term is greater than $s\left(p_{e}^{m}-d\right) \frac{d F\left(p_{e}^{m}\right)}{d c_{e}}$ where $F\left(p_{e}^{m}\right)$ is given by (8) rather than (9). Thus, the effect of $c_{e}$ on expected surplus from signing is greater than $\frac{\left(p_{e}^{m}-p_{0}\right) q\left(p_{0}\right)}{\left(p_{e}^{m}-c_{e}\right)^{2} q\left(p_{e}^{m}\right)}\left(s\left(p_{e}^{m}-d\right)-s\left(p^{m}\right)\right)>0$ (because $\left.\frac{d F\left(p_{e}^{m}\right)}{d c_{e}}=\frac{\left(p_{e}^{m}-p_{0}\right) q\left(p_{0}\right)}{\left(p_{e}^{m}-c_{e}\right)^{2} q\left(p_{e}^{m}\right)}\right)$. The consumer surplus from rejecting is clearly independent of $c_{e}$ because the price is fixed at c. Thus, the expected loss in consumer surplus from signing the loyalty discount contract is decreasing in $c_{e}$. Thus, the amount necessary to compensate one buyer for signing the loyalty discount is decreasing in $c_{e}$. Because the incumbent plays a mixed pricing strategy which includes in its support charging the monopoly price to all signing buyers, its profit is simply the monopoly profit per buyer times the number of signing buyers. Thus, the incumbent will pay up to the monopoly profit per buyer to induce buyers to sign. So, if the amount necessary to compensate one buyer for signing the loyalty discount contract is less than the monopoly profit per buyer at $\bar{c}_{e}$, then it is less for any $c_{e}>\bar{c}_{e}$. (ii) Because Proposition 1(iii) says that the incumbent's distribution function is decreasing in $\theta$, this implies that the expected consumer surplus from being the only signer is increasing in $N$ (because $\theta=1 / N$ if a buyer is the only signer). The consumer surplus from rejecting is clearly independent of $N$ because the price is fixed at $c$. Thus, the expected loss in consumer surplus from signing the loyalty discount contract is decreasing in $N$. Thus, the amount necessary to compensate one buyer for signing the loyalty discount is decreasing in $N$. So, if the amount necessary to compensate one buyer for signing the loyalty discount contract is less than the monopoly profit per buyer at $\bar{N}$, then it is less for any $N>\bar{N}$. Q.E.D. 
Proposition 3 can be thought of as a comparative statics result for Proposition 2 (A). We know that if the entrant's innovation is large enough that Assumption $(*)$ is not satisfied, no buyer will sign a loyalty discount contract. Thus, part (i) tells that there is some critical level of the entrant's costs such that the incumbent can induce at least one buyer to sign a loyalty discount contract if and only if the entrant's costs are greater than this critical level. In other words, if the entrant's cost advantage is too great, then loyalty discount contracts will be completely ineffective in limiting the entrant's market share and softening competition. We also know that if there is only one buyer in the market, this buyer will not sign a loyalty discount contract. Thus, part (ii) says that there is some critical number of buyers such that the incumbent can induce at least one buyer to sign a loyalty discount contract if and only if the number of buyers exceeds this critical level. Because buyers impose a negative externality on each other when they sign a loyalty discount contract, each buyer internalizes less of the cost if there are more buyers. This makes loyalty discount contracts more effective in softening competition.

Before proceeding, let's pause to consider the robustness of our results to the buyer's option to breach the loyalty discount contract and pay damages. While we will not do a complete analysis here, it is worth noting that the result of the mixed strategy equilibrium will sometimes be that the incumbent's loyalty discounted price will be lower than the entrant's price. In those situations, there is no incentive for a buyer to breach. Even in situations in which the entrant's price is lower than the loyalty discounted price, the entrant's price will generally exceed its costs. This means that even if total surplus is higher with breach, the joint surplus of the incumbent and buyer may not be higher with breach because breach transfers profit to the entrant. Lastly, note that even if a buyer does breach with positive probability, if the buyer must pay expectation damages, the incumbent can still earn the same level of profit. ${ }^{13}$ To see this, notice that the incumbent still has the option to charge $p^{m}+d$ to free buyers and $p^{m}$ to committed buyers. If those committed buyers breach, expectation damages will still ensure that the incumbent earns the monopoly profit on all of its committed buyers. Thus, any pricing equilibrium with breach must earn the

\footnotetext{
${ }^{13}$ Further, in some circumstances, such as when rebates are denied, a breaching buyer will have to pay more than expectation damages (Elhauge 2009 p.205-6).
} 
incumbent a total profit (in expectation) equal to its monopoly profit from its committed buyers. ${ }^{14}$ Thus, the possibility of breach will not reduce the amount the incumbent will pay buyers to sign the loyalty discount contracts. Furthermore, it does not change the fact that a buyer externalizes some of its costs of signing the contract because signing the contract will induce the incumbent to price less aggressively even if it expects breach. This less aggressive pricing by the incumbent will still induce less aggressive pricing by the entrant, hence other buyers bear part of the social cost from one buyer signing the contract. So, while it is possible that breach could reduce the magnitude of this externality in some instances, it cannot eliminate it. So, at most, allowing buyer breach might reduce the situations where loyalty discount contracts are enforceable but would not eliminate it.

\subsection{Numerical Analysis-Linear Demand Case}

With fully general demand functions, we have shown that with enough buyers and a small enough entrant cost advantage, the incumbent can use loyalty discounts to soften competition in any equilibrium. That said, at that level of generality, we cannot calculate how many buyers is enough or how small the entrant's cost advantage must be in order for loyalty discounts to be effective. To get some purchase on these issues, we now assume a linear demand function, $q(p)=1-p$. This generalizes to any linear demand function because any function $a-b \tilde{p}$ is equivalent to a demand function of $1-p$ for $a$ units of the good priced in monetary unit that is $a / b$ of the original monetary unit. With linear demand it is possible to solve (5) explicitly for $p_{0}$. Because the explict functions are messy, we will relegate them to the appendix. This gives closed form expressions for both $F$ and $F_{e}$. Furthermore, the assumption of linear demand gives a closed form expression for consumer surplus for any given price, and for $I$ and $E$ 's monopoly price. This means we can write expected consumer surplus for both committed and free buyers as a function of the number of committed buyers, $n$.

\footnotetext{
${ }^{14}$ This follows since in the mixed strategy equilibrium, the incumbent charges its monopoly price with positive probability and serves only the committed buyers when it does this. So, if committed buyers breach, the monopoly profit from selling to them is what the incumbent loses.
} 


\subsubsection{Numerical Analysis-Conditions for Exclusion}

As detailed in the appendix, the expected consumer surplus functions contain integral terms. Unfortunately, it is not possible to get closed-form solutions for these integrals for arbitrary $c_{E}$ and $d$. Thus, we will proceed by numerical analysis. For any given set of parameter values, we can numerically calculate the consumer surplus functions to determine the loss in expected consumer surplus a buyer would receive from signing a loyalty discount contract with any given discount $d$ given that exactly $n$ other buyers will sign the contract. This gives the maximum amount the incumbent must pay to induce $n+1$ buyers to sign a loyalty discount contract with discount $d$. We call this the signing cost for $n$ signers. (It is the maximum amount because it may be cheaper to induce $n^{\prime}+1$ buyers to sign the contract for some $n^{\prime}>n$. Thus, if buyers expect $n^{\prime}$ other buyers to sign the contract, the incumbent may not need to pay as much.) We then numerically calculate the number of buyers, $n$, out of the total number of buyers, $N$, for which this signing cost reaches its maximum. This gives the maximum amount the incumbent would have to pay to induce all buyers to sign the loyalty discount contracts. ${ }^{15}$ We call this the maximum signing cost for any given discount, $d$. We then find, numerically, the discount, $d$, that minimizes this maximum signing cost.

This procedure allows us to determine, for any given $c, c_{e}$, and $N$, the discount, $d$, that allows the firm to induce all buyers to sign a loyalty discount contract (given any beliefs about what other buyers will do) for the minimum up-front transfer, $t$. (The next subsection focuses on the optimal $d$.) We can further determine how large this minimum $t$ has to be (this is simply the value of the maximum signing cost at the $d$ that minimizes this value) and whether it is less than the firm's profit from inducing the buyer to sign. This profit is simply $(1-c)^{2} / 4$, the monopoly profit per buyer. Using numerical root finding, we can also determine the maximum value of $c_{E}$ (for any given $c$ and $N$ ) for which the firm can induce all buyers to sign a loyalty discount contract in any equilibrium. ${ }^{16}$

\footnotetext{
${ }^{15}$ This is the maximum because then every buyer will sign for any belief about how many other buyers will sign.

${ }^{16}$ While Proposition 3 tells us that the cost of obtaining the first signer is monotonically decreasing in $c_{e}$, we have not proved analytically that the cost of obtaining any number of signers is monotonically decreasing in $c_{e}$. That said, numerical analysis for the linear case has revealed no instances where the minimum (over $d$ ) of the maximum cost of inducing all buyers to sign is increasing in $c_{e}$. Furthermore, as we discuss in more detail below, except when the number of buyers is very large, this analysis also shows that the maximum
} 
We use this procedure to find this maximum value for $c_{E}$ for every integer value of $N$ between 3 and 20 (for $N=2$ we observed that it is not possible to induce one buyer to sign a loyalty discount if she believes the other buyer will not sign even if $c_{E}=c$ ) and for $c \in\{.1, .2, \ldots, .9\}$. Using this data, we then run a regression to generate a functional form for finding this maximum value for $c_{E}$ as a function of $N$ and $c$. We find that

$$
\begin{aligned}
\hat{c}_{E}= & 0.2080+0.7594 c+0.0361 c^{2}+0.0066 N-0.0102 c N+0.0040 c^{2} N \\
& -0.2408 \log [N]+0.2736 c \log [N]-0.0362 c^{2} \log [N]
\end{aligned}
$$

All of these coefficients have p-values of less than .01. The R-Squared for this regression is .99999 .

It is probably easiest to get a sense of how effective loyalty discounts can be in this model to look at this expression graphically. Figure 1 uses (11) to plot $\hat{c}_{E} / c$ as a function of $c$ with $N=3,7$, and 20. With only three buyers, the incumbent can use loyalty discounts to completely foreclose buyers if the ratio of the entrant's cost to the incumbent's costs is above the thin solid line. So, if the incumbent's costs are less than about 0.04, then it can induce all buyers to sign a loyalty discount contract for any beliefs about what other buyers will do even if the entrant can produce at no cost at all. With only three buyers, however, the effectiveness of loyalty discounts falls quickly as the incumbent's cost increase. Once the incumbent's costs rise to 0.2 , loyalty discounts foreclose all buyers under any beliefs if and only if the entrant's costs are at least $85 \%$ of the incumbent's. If the incumbent's costs are 0.5 , this number rises to about $96 \%$. When the number of buyers rises to seven, loyalty discounts become effective for a much larger range of costs. If the incumbent's costs are 0.15 , it can completely foreclose (again, for any beliefs) an entrant with zero costs. At costs of 0.5 , the incumbent can still completely foreclose the entrant under any set of buyer beliefs as long as the entrant's costs are no less than $79 \%$ of the incumbent's. Even at costs of 0.8, the incumbent can completely foreclose the entrant under any set of buyer beliefs as long as the entrant has no more than a 5\% cost advantage. As the figure shows, with 20 buyers,

cost occurs when buyers expect no other buyers to sign. This is precisely the case where Proposition 3 proves that the cost is monotonically decreasing in $c_{e}$. 
foreclosure under any beliefs is even easier, especially if the incumbent's costs are not too large.

Figure 2 allows us to see more directly the effect of increasing the number of buyers by using (11) to plot $\hat{c}_{E} / c$ as a function of $N$ with $c=0.2,0.5$, and 0.8 . This figure shows that increasing the number of buyers allows the incumbent to completely foreclose the entrant under any set of buyer beliefs even as the entrant's cost advantage increases. The magnitude of the effect of increasing the number of buyers is diminishing as the number of buyer's increases and is more pronounced if the incumbent's costs are lower. Thus, if the incumbent's cost are 0.8 , even with 20 buyers the entrant can be completely foreclosed under all buyer beliefs only if it's cost advantage is less than $10 \%$ (though, this is still a non-trivial cost advantage). On the other hand, if the incumbent's costs are 0.2 , it can completely foreclose an entrant under any set of buyer beliefs through loyalty discounts if it has at least 9 buyers even if the entrant's costs are zero.

It is worth noting that when there are 20 or fewer buyers, the maximum value for $c_{E}$ always occurred when buyers believed that no other buyer would sign the loyalty discount contract. That is, if the incumbent can profitably get one buyer to sign a loyalty discount contract then it can profitably get all buyers to do so. It is not the case, however, that inducing the first signer is always the most costly. For example, if $c_{E}$ is substantially above the maximum value necessary for there to exist an equilibrium in which no buyers sign the loyalty discount contract, then it can most costly for the incumbent to induce signing where buyers believe that some, but not all, other buyers will sign the loyalty contracts. Nonetheless, in every case that we examined, it was always most profitable to sign all the buyers rather than to pay a smaller amount and sign less than all buyers. That is, we never found a case in which there was an equilibrium in which some, but not all, buyers sign the loyalty discount contract.

The results from the linear demand analysis give some insight into the likely importance of the possibility results in Proposition 2. Recall that part A of Proposition 2 tells us that if there are enough buyers and the entrant's cost advantage is small enough, there is no equilibrium in which at least one buyer does not sign a loyalty discount contract. Part B says that if there are enough buyers, there exists an equilibrium in which all buyers sign a loyalty 
discount contract. Our linear demand results make four main points that demonstrate that these possibility results likely have significant practical impact. These are summarized in the following remark.

Remark With linear demand and 20 or fewer buyers:

1. If the incumbent can profitably induce one buyer to sign a loyalty discount contract then it can profitably create a unique equilibrium in which all buyers sign a loyalty discount contract.

2. If the entrant's cost advantage is small, it takes only three buyers to create this unique exclusionary equilibrium.

3. The larger the potential market (based on demand when price equals cost), the easier it is for the incumbent to create this unique exclusionary equilibrium.

4. The incumbent can create a unique exclusionary equilibrium for a substantial range of parameters even if the entrant has a non-trivial cost advantage. For example, if the entrant has no more than a 10\% cost advantage, the incumbent can create a unique exclusionary equilibrium with three buyers if its costs are less than $28 \%$ of the choke price, with seven buyers if its costs are less than $68 \%$ of the choke price, and with 20 buyers if its costs are less than $80 \%$ of the choke price.

In our model, with zero costs of entry, entry is always efficient. Thus, our linear demand results show that there is substantial scope for an incumbent to profitably use loyalty discounts to foreclose efficient entry, reducing both productive efficiency and consumer surplus. Notice that this occurs, unlike in prior models of exclusive dealing, without any economies of scale and even with buyers with independent demands.

\subsubsection{Numerical Analysis-Optimal Loyalty Discount}

In this part, instead of analyzing the conditions under which some loyalty discount contract can exclude an entrant, we analyze what loyalty discount would be optimal for the incumbent given that using loyalty discounts is profitable for the incumbent. As with determining the 
conditions for exclusions, we proceed via numerical anlaysis. In this case, we randomly drew parameter values for the incumbent's cost, $c$, the entrant's cost, $c_{E}$, and the number of buyers, $N$. We drew $c$ from a uniform distribution between zero and one. We drew $c_{E}$ from a uniform distribution between $\operatorname{Max}\{0,2 c-1\}$ and $c$. This ensures both that the entrant's innovation is non-drastic and that it has a cost advantage over the incumbent. ${ }^{17}$ We drew $N$ from the integers between three and 20 with each one equally likely. For each set of parameters that we drew, we calclulated, as above, the discount, $d$, that minimized the incumbent's maximum cost of signing each buyer, assuming that the each buyer assumed that the number of other buyers who would sign the loyalty discount contract was the number that would maximize the cost of inducing buyers to sign the contract. ${ }^{18}$ Thus, for each set of paramter values, we determined the optimal discount and the cost of signing up buyers under the assumption that each buyer's belief about the number of other buyers who would sign the contract is that which would maximize the signing cost.

We did 1500 draws from these distributions of parameter values. Of these 1500 draws, using loyalty discounts was profitable (and effectively excluded the entrant) in just over half of the draws (763). ${ }^{19}$ We used these 763 cases to analyze (using linear regression analysis) the optimal loyalty discount in situations where the incumbent would use them. We found that a relatively simple, and easy to interpret specification, explained over 90 percent of the variation in the optimal discount (R-squared of .901):

$$
\hat{d}=0.023-0.091 c-0.430 c_{E}+0.201 \log [N]
$$

All coefficients are significant at the .05 level and the coefficients of $c_{E}$ and $\log [N]$ are significant at well-beyond the .001 level. This tells us that the incumbent offers contracts with higher discounts the more firms there are. ${ }^{20}$ Increasing both the entrant's and the

\footnotetext{
${ }^{17}$ This restriction on the entrant's cost is actually somewhat weaker than Assumption $(*)$, which explains why loyalty discounts were not profitable in so many cases.

${ }^{18}$ We make this assumption to examine the worst case for loyalty discounts for the incumbent.

${ }^{19}$ Not surprisingly, given the results in the last subsection, the cases where loyalty discounts were not profitable were those where the entrant's cost advantage was large and the number of buyers was small, and the market was small.

${ }^{20}$ Recall, that this result does depend on buyers making the worst-case assumption that the number of other buyers who will agree to the loyalty commitment is the number that maximizes the cost of the
} 
incumbent's costs result in lower discounts, though the effect is much stronger for changes in the entrant's costs. It is worth remembering that a larger discount is not necessarily good for the signing buyer because it leads the incumbent to price less aggressively. To get a sense of the magnitude of the discount, note that if the incumbent's costs are 0.5 and the entrant's are 0.45 (a 10 percent cost advantage), if there are 10 buyers, then the optimal discount is about 0.25 , which is one-third of the incumbent's profit-maximizing monopoly price, or about one-quarter of the optimal monopoly price before the discount. ${ }^{21}$ Figure 3 gives a graph of the optimal discount for three different levels of the incumbent's costs when

the entrant has a ten percent cost advantage as a function of the number of buyers. For $c=0.7$, the optimal discount is negative for fewer than five buyers, but because this is a region in which it is not profitable to offer the discount, this region should be ignored.

\section{Loyalty Discounts Without Buyer Commitment}

In the last section, we considered loyalty discounts contracts that were effectively exclusive contracts combined with a discount. In this section we consider loyalty discount contracts that bind the incumbent to offer the discount if the covered buyer buys from the incumbent but do not commit this buyer to buy from the incumbent. Our model is identical to the model in section 2.1 except for the following differences. First, in period 1 we allow the incumbent to sign buyers up sequentially. We do this because, as will become obvious below, loyalty discounts without buyer commitment are never profitable for the incumbent if all buyers are covered. Second, while we continue to believe that simultaneous pricing is the most relevant, in period 2 we will consider both types of sequential pricing (entrant chooses price first and the incumbent chooses price first) in addition to considering simultaneous pricing. We do this because prior papers on loyalty discounts without commitment (specifically Elhauge (2009)) assumed that buyers would accept these offers. So, the buyer acceptance decision has not been previously analyzed in for any of these cases. Lastly, because we are no longer assuming buyer commitment, in period 3, both covered and non-covered buyers have a choice

commitment to the buyer (and, hence, to the incumbent).

${ }^{21}$ The profit-maximizng monopoly price if $q=1-p$ is $(1+c) / 2$. 
of supplier if entrant has entered. If $p_{f}-d<p_{e} \leq p_{f}$, then only free buyers purchase from $E$, and covered buyers purchase from $I$. Thus, I's profit is $\theta\left(p_{f}-d-c\right) q\left(p_{f}-d\right)$, while $E$ 's profit is $(1-\theta)\left(p_{e}-c_{e}\right) q\left(p_{e}\right)$. If $p_{e}>p_{f}$, then all buyers purchase from $I$. Thus, I's profit is $\theta\left(p_{f}-d-c\right) q\left(p_{f}-d\right)+(1-\theta)\left(p_{f}-c\right) q\left(p_{f}\right)$ while $E$ 's profit is zero. If $p_{f}-d \geq p_{e}$, then

all buyers purchase from $E$, and thus $E$ 's profit is $\left(p_{e}-c_{e}\right) q\left(p_{e}\right)$ and $I$ 's profit is zero. In what follows, in the interest of reducing notation, we will ignore integer constraints on the number of buyers covered.

\subsection{Entrant Chooses Price First}

If the entrant chooses a price $p_{e}$, then the incumbent will either choose $p_{f}=p_{e}-\varepsilon$ and sell to the entire market or it will choose $p_{f}=p_{e}+d-\varepsilon$ and sell only to covered buyers. Letting $\varepsilon \rightarrow 0$, we have that the incumbent sells only to covered buyers if and only if the following holds:

$$
\theta\left(p_{e}-c\right) q\left(p_{e}\right)-\left\{\theta\left(p_{e}-d-c\right) q\left(p_{e}-d\right)+(1-\theta)\left(p_{e}-c\right) q\left(p_{e}\right)\right\} \geq 0
$$

Clearly, the entrant would never choose a price for which this condition does not hold, because then it would earn zero profits. The left hand side is decreasing in $p_{e}$ as long as profits are concave in prices and $p_{e}<p^{m}$. Furthermore, the left hand side is clearly positive at $p_{e}=c$ for any $d>0$. Thus, the incumbent will sell only to covered buyers so long as the entrant chooses a small enough price (which can exceed $c$ ). If the discount is large enough, it is possible that the incumbent will sell only to covered buyers even if $p_{e}=p_{e}^{m}$. Let $\overline{p_{e}}$ be the price that satisfies (13) at equality if it exists and is smaller than $p_{e}^{m}$, or alternatively, $p_{e}^{m}$.

By totally differentiating (13) with repsect to $\theta$, we can determine how $\overline{p_{e}}$ varies with $\theta$ for $\overline{p_{e}}<p_{e}^{m}$ :

$$
\frac{d \overline{p_{e}}}{d \theta}=\frac{2\left(\overline{p_{e}}-c\right) q\left(\overline{p_{e}}\right)-\left(\overline{p_{e}}-d-c\right) q\left(\overline{p_{e}}-d\right)}{(1-2 \theta)\left\{q\left(\overline{p_{e}}\right)+\left(\overline{p_{e}}-c\right) q^{\prime}\left(\overline{p_{e}}\right)\right\}+\theta\left\{q\left(\overline{p_{e}}-d\right)+\left(\overline{p_{e}}-d-c\right) q^{\prime}\left(\overline{p_{e}}-d\right)\right\}}>0
$$

This is positive for $\theta<1 / 2$ because the incumbent's profit is greater at $\overline{p_{e}}$ than $\overline{p_{e}}-d$ because $\overline{p_{e}} \leq p_{e}^{m}$ and because the incumbent's profit is increasing at both $\overline{p_{e}}$ and $\overline{p_{e}}-d$. Thus, for 
$\theta<1 / 2$ (and for larger $\theta$ we can see that $\overline{p_{e}}=p_{e}^{m}$ ), $\overline{p_{e}}$ is increasing in $\theta$. That is, the higher the share of buyers covered by the loyalty discount, the higher the price the entrant can choose without the incumbent undercutting this price for non-covered buyers (which would eliminate the entrant's profit). Thus, (13) implicitly defines $\overline{p_{e}}$ as a non-decreasing (strictly increasing when $\left.\overline{p_{e}} \leq p_{e}^{m}\right)$ function of $\theta$.

The entrant can also choose $p_{e}=c$ and sell to all buyers. It will prefer to choose $\overline{p_{e}}$ if and only if:

$$
(1-\theta)\left(\overline{p_{e}}-c_{e}\right) q\left(\overline{p_{e}}\right)-\left(c-c_{e}\right) q(c) \geq 0
$$

Clearly, this is only satisfied if $\theta$, the fraction of covered buyers, is not too large.

The entrant will never choose a price higher than $p_{e}^{m}$. To see if loyalty discounts without commitment can support this price, note that (14) implies a maximum theta of $\bar{\theta}=\frac{\left(p_{e}^{m}-c_{e}\right) q\left(p_{e}^{m}\right)-\left(c-c_{e}\right) q(c)}{\left(p_{e}^{m}-c_{e}\right) q\left(p_{e}^{m}\right)}$. Next, we see if we can satisfy (13) at $\bar{\theta}$. If the entrant's innovation satisfies Assumption $(*)$ (so that $p_{e}^{m}>c$ ), then $\bar{\theta}>0$. If there is no restriction on $d$ and $\theta>0,(13)$ can always be satisfied because the incumbent's loss from selling to even one covered buyer at a price of $p_{e}-d$ can be made arbitrarily large by making $d$ arbitrarily large (so that the incumbent has to pay the covered buyer an arbitrarily large amount to buy the good).

Alternatively, one might imagine that $p_{e}-d$ must be non-negative (the incumbent cannot offer a negative price to covered buyers) or that $p_{e}-d \geq c$ (the incumbent cannot price below cost to covered buyers). If we impose the first constraint, then loyalty discounts can support the entrant choosing $p_{e}^{m}$ if and only if:

$$
(2 \bar{\theta}-1)\left(p_{e}^{m}-c\right) q\left(p_{e}^{m}\right)+\bar{\theta} c q(0) \geq 0
$$

The reason is that if this inequality is satisfied, then the incumbent earns more profit from selling only to covered buyers at the entrant's monopoly price than it would earn from selling to uncovered buyers at the entrant's monopoly price and selling to covered buyers at a price of zero (which would give it losses of $c q(0)$ ). The left hand side of this is increasing in $\theta$. This is clearly satisfied for any $\bar{\theta} \geq 1 / 2$ and could be satisfied for much lower $\bar{\theta}$ if the incumbent's losses at a price of zero are substantial. If we impose the second constraint (no 
predatory pricing), then loyalty discounts can support the entrant choosing $p_{e}^{m}$ if and only if $\bar{\theta} \geq 1 / 2$. Let $\hat{\theta}=\frac{\left(p_{e}^{m}-c\right) q\left(p_{e}^{m}\right)}{2\left(p_{e}^{m}-c\right) q\left(p_{e}^{m}\right)+c q(0)}$. We have now proven the following lemma.

Lemma 3 If the discounted price must be non-negative, then loyalty discounts without buyer commitment can support an entrant price of $p_{e}^{m}$ if $\theta \in[\hat{\theta}, \bar{\theta}]$. If the discounted price cannot be below c, then loyalty discounts without buyer commitment can support an entrant price of $p_{e}^{m}$ if $\theta \in[1 / 2, \bar{\theta}]$. In either case, the incumbent just undercuts $p_{e}^{m}$ to covered buyers and does not sell to uncovered buyers.

It remains to be seen whether or not the incumbent can induce this fraction of buyers to agree to be covered by a loyalty discount. While one might think that this is trivial because agreeing to the discount involves does not bind a buyer, this is does not mean that agreeing is necessarily costless to the buyer. As the fraction of covered buyers increases, as long as it is below $\hat{\theta}$ or $1 / 2$, the greater is the price the entrant will choose. Because the incumbent chooses a price so that the discounted price just undercuts the entrant's price, this means that agreeing to be covered by the discount can increase the price the buyer expects to pay if the buyer expects that enough other buyers will choose not to be covered by the discount. In this case, the incumbent might have to pay buyers to induce them to be covered.

Whether this will be possible will depend on the number of buyers and the entrant's cost advantage. If there are only two buyers, for example, then buyers will never agree to be covered by loyalty discounts without buyer commitment for any upfront payment that the incumbent would be willing to make. The incumbent would never want to cover both buyers because then the entrant would have to charge $c$ to stop the incubment from undercutting it. If the incumbent signs up only one buyer, then this buyer loses consumer surplus because of the higher price, but the incumbent only gains from the higher price through sales to this one buyer. Because elevating prices above costs is inefficient (increased profits are less than lost consumer surplus), the incumbent cannot pay one buyer to accept. With only one covered buyer, there is no negative externality on other buyers that the incumbent can benefit from (there is a negative externality, but this benefits the entrant who sells to the non-covered buyer at a higher price). With more buyers, however, it is possible for the incumbent to profitably induce enough buyers to sign the loyalty discount contract so that 
prices are elevated to $p_{e}^{m}$ as long as the entrant's cost advantage is not too great.

Proposition 4 (A) If there is no constraint on $d$, then the incumbent can induce $\bar{\theta} N$ buyers to be covered by a loyalty discount without buyer commitment in exchange for an arbitrarily small payment if $\bar{\theta} N \geq \operatorname{Max}\left\{2, \frac{s(c)-s\left(p_{e}^{m}\right)}{\left(p_{e}^{m}-c\right) q\left(p_{e}^{m}\right)}\right\}$ leading to $p_{e}=p_{e}^{m}$ and $p_{f}-d=$ $p_{e}^{m}-\varepsilon$. (B) If the discounted price is constrained to be non-negative, then the incumbent can induce $\bar{\theta} N$ buyers to be covered by a loyalty discount without buyer commitment in exchange for an arbitrarily small payment if $\bar{\theta} N \geq \operatorname{Max}\left\{\hat{\theta} N, \frac{\hat{\theta} N\left(s(c)-s\left(p_{e}^{m}\right)\right)}{\left(p_{e}^{m}-c\right) q\left(p_{e}^{m}\right)}\right\}$. This condition will always be met if demand is concave and the entrant's cost advantage is sufficiently small. When this condition is met, prices will be $p_{e}=p_{e}^{m}$ and $p_{f}-d=$ $p_{e}^{m}-\varepsilon$. (C) If the discounted price is constrained to not be below $c$, then the incumbent can induce $\bar{\theta} N$ buyers to be covered by a loyalty discount without buyer commitment in exchange for an arbitrarily small payment if $\bar{\theta} N \geq \operatorname{Max}\left\{N / 2, \frac{N\left(s(c)-s\left(p_{e}^{m}\right)\right)}{2\left(p_{e}^{m}-c\right) q\left(p_{e}^{m}\right)}\right\}$. This condition will always be met if demand is concave and the entrant's cost advantage is sufficiently small. When this condition is met, prices will be $p_{e}=p_{e}^{m}$ and $p_{f}-d=$ $p_{e}^{m}-\varepsilon$.

Proof. (A) By choosing an arbitrarily large $d$, the incumbent can guarantee that (13) is satisfied at $p_{e}^{m}$ for any $\theta>0$. Thus, the incumbent will respond to the entrant's price of $p_{e}^{m}$ by offering $p_{f}=p_{e}+d-\varepsilon$ and selling only to covered buyers. The entrant will choose $p_{e}^{m}$ rather than $c$ (which would enable it to sell to all buyers) as long as $\theta \leq \bar{\theta}$. Thus, the incumbent's can maximize its profit by getting $\bar{\theta} N$ buyers to be covered by the discount. It only remains to show that these buyers will accept the discount for an arbitrarily small payment. To show this, consider the case in which $N-\bar{\theta} N$ buyers have rejected the incumbent's offer. If the next buyer believes that all future buyers will also reject, then she will accept the discount if she is paid $s(c)-s\left(p_{e}^{m}\right)$, her loss of consumer surplus from paying a price of $p_{e}^{m}$ rather than $c$. Because (13) can be satisfied at $p_{e}^{m}$ for large enough $d$ even after only one buyer has signed, all subsequent buyers know that their decision to be covered will not affect equilibrium prices. So, none of these buyers need more than a trivial payment to accept the discount. Thus, even if $N-\bar{\theta} N$ buyers have already rejected the incumbent's discount, the incumbent can get the remaining buyers covered with only a total payment of $s(c)-s\left(p_{e}^{m}\right)$. 
This is profitable so long as $s(c)-s\left(p_{e}^{m}\right)<\bar{\theta} N\left(\left(p_{e}^{m}-c\right) q\left(p_{e}^{m}\right)\right)$. This never holds if $\bar{\theta} N<2$. Because the first $N-\bar{\theta} N$ expect the incumbent to sign $\bar{\theta} N$ buyers even if they reject the incumbent's offer, rejecting the offer does not increase their consumer surplus. Hence, the first buyer approached will accept being covered for only a trivial sidepayment, which means that all subsequent buyers approached will also.

(B) First, we define the following terms to simplify the later notation. Let $\pi_{E}^{m}=$ $\left(p_{e}^{m}-c_{e}\right) q\left(p_{e}^{m}\right)$ be the entrant's monopoly profit per buyer. Let $\pi_{E}^{c}=\left(c-c_{e}\right) q(c)$ be the entrant's profit per buyer if it charges a price of $c$. Let $\pi_{e}^{p_{e}^{m}}=\left(p_{e}^{m}-c\right) q\left(p_{e}^{m}\right)$ be the incumbent's profit per buyer it serves at the entrant's monopoly price. Let $\pi^{0}=c q(c)$ be the incumbent's loss per buyer it serves at a price of zero.

If the incumbent cannot charge a negative price, then the maximum loss it can suffer from selling to covered buyers is $c q(0)$. Given this, the entrant will choose $p_{e}^{m}$ if and only if the fraction of covered buyers is at least $\hat{\theta}$ but less than $\bar{\theta}$. Thus, once the incumbent has $\hat{\theta} N$ covered buyers, all remaining buyers up until $\bar{\theta} N$ do not require compensation to be covered because they will pay the same price, $p_{e}^{m}$, whether they are covered or not because the entrant will offer a price of $p_{e}^{m}$ once there are $\hat{\theta} N$ covered buyers but not more than $\bar{\theta} N$ covered buyers. We will assume the worst case for making such compensation profitable. Specifically, we will ask if the incumbent can obtain agreement to be covered from $\bar{\theta} N$ buyers when $N-\bar{\theta} N$ buyers have already rejected the offer. We will then assume that remaining buyers believe that if they reject the incumbent's offer, then all future buyers will reject, but if they accept, then enough buyers will accept ( $\hat{\theta} N$ buyers) so that they will face a price of $p_{e}^{m}$. Lastly, contrary to fact, we will assume that even when some buyers have already accepted, until $\hat{\theta} N$ buyers have accepted, the buyers believe that rejecting the offer will enable them to buy at the competitive price of $c$. We make this assumption simply because for a general demand curve, we cannot get an explicit formula for $\overline{p_{e}}$ as a function of the number of buyers who have already accepted. Thus, $\hat{\theta} N$ buyers must receive compensation of $s(c)-s\left(p_{e}^{m}\right)$.

This means it is profitable for the incumbent to get $\bar{\theta} N$ buyers to accept if:

$$
\bar{\theta} N \pi^{p_{e}^{m}}-\hat{\theta} N\left(s(c)-s\left(p_{e}^{m}\right)\right)>0
$$


Substituting for $\bar{\theta}$ and $\hat{\theta}$, we can write this as:

$$
\frac{\pi_{E}^{m}-\pi_{E}^{c}}{\pi_{E}^{m}} \pi^{p_{e}^{m}}-\frac{\pi^{p_{e}^{m}}}{2 \pi^{p_{e}^{m}}+\pi^{0}}\left(s(c)-s\left(p_{e}^{m}\right)\right)>0
$$

We know that $s(c)-s\left(p_{e}^{m}\right)=\int_{c}^{p_{e}^{m}} q(x) d x<\left(p_{e}^{m}-c\right) q(c)$. Thus, a sufficient condition is:

$$
\left(\pi_{E}^{m}-\pi_{E}^{c}\right)\left(2 \pi_{e}^{p_{e}^{m}}+\pi^{0}\right)-\pi_{E}^{m}\left(p_{e}^{m}-c\right) q(c)>0
$$

It is easy to see that if the entrant's innovation is almost drastic (so that $p_{e}^{m}$ is only slightly larger than $c$ ), $\pi_{E}^{m}-\pi_{E}^{c}$ close to zero, then this sufficient condition will not hold. On the other hand, if the entrant's cost advantage is very small, $\pi_{E}^{c}$ almost zero and $\pi^{p_{e}^{m}}$ is almost as big as $\pi_{E}^{m}$, then this is $\pi_{E}^{m}\left[\pi^{0}+\left(p_{e}^{m}-c\right)\left(2 q\left(p_{e}^{m}\right)-q(c)\right)\right]$. This is always positive if $q$ is concave because the monopoly quantity exceeds half the competitive quantity for concave demand.

As in (A), because the first $N-\bar{\theta} N$ expect the incumbent to $\operatorname{sign} \bar{\theta} N$ buyers even if they reject the incumbent's offer, rejecting the offer does not increase their consumer surplus. Hence, the first buyer approached will accept being covered for only a trivial sidepayment, which means that all subsequent buyers approached will also.

(C) This follows from the proof of (B) because this proof continues to be valid if we take $\pi^{0}=0$, as would be the case if the discounted price equals the incumbent's cost. Q.E.D.

If the incumbent can offer an arbitrarily large discount, then the incumbent never wants to sell to both covered and non-covered buyers because charging a price that meets the entrant's price for non-covered buyers will result in arbitrarily large losses from selling to each covered buyer. Thus, having one covered buyer is sufficient to ensure that prices are at the entrant's monopoly price. So, once the incumbent has signed up one buyer, all remaining buyers expect to pay the entrant's monopoly price whether they are covered or not. Hence they will sign up for a trivial side-payment. In order to ensure that one buyer will sign up, the incumbent has to be willing to pay that one buyer her loss of consumer surplus from paying the monopoly price rather than the competitive price. But, if it is profitable to do so, the incumbent needn't actually pay this amount because buyers prior to $N-\bar{\theta} N$ expect 
the incumbent to offer buyer $N-\bar{\theta} N$ her lost consumer surplus to sign $\left(s(c)-s\left(p_{e}^{m}\right)\right)$, so they might as well sign for any amount.

If the incumbent's discount is constrained so that it cannot offer a negative price, then its loss per covered buyer is bounded, hence it needs to sign up more buyers to ensure it does not have an incentive to undercut the entrant's price of $p_{e}^{m}$. To eliminate an equilibrium in which all buyers reject being covered thinking that all subsequent buyers will reject, the incumbent has to be able to reimburse $\hat{\theta} N$ buyers for their loss in consumer surplus out of the profits of selling to $\bar{\theta} N$ covered buyers at the entrant's monopoly price. The buyers' loss in consumer surplus is less than $s(c)-s\left(p_{e}^{m}\right)$ each. $^{22}$ Thus, if $\bar{\theta} N \pi_{e}^{p_{e}^{m}}-\hat{\theta} N\left(s(c)-s\left(p_{e}^{m}\right)\right)>0$, the incumbent always has a credible threat to sign up a sufficient number of buyers.

One might think that this is easier to satisfy as the entrant's costs are smaller because the lost consumer surplus is smaller. However, smaller entrant costs also reduce $\bar{\theta}$, the maximum fraction of buyers that can be covered without the entrant charging $c$ and selling to all buyers. It turns out that this latter effect matters more when the entrant's innovation is close to drastic $\left((16)\right.$ is decreasing in $c_{e}$ when $c_{e}$ is such that $\left.p_{e}^{m}=c\right)$. But, if the entrant's costs are close to the incumbent's ${ }^{23}$ and demand is concave, then the incumbent can always induce enough buyers to agree to be covered for a trivial side-payment, leading the market to be divided between the incumbent and the entrant, with all buyers paying the entrant's optimal monopoly price. Thus, even without commiting buyers to buy only from the incumbent, if the entrant prices first, loyalty discounts can lead to a divided market and higher prices.

\subsection{Incumbent Chooses Price First}

If the incumbent chooses its price to free buyers, $p_{f}$, first, then the entrant will either choose to price at $p_{e}=\operatorname{Min}\left\{p_{f}, p_{e}^{m}\right\}$-selling only to uncovered buyers-or the entrant will choose

\footnotetext{
${ }^{22}$ If the first buyer to sign believes that her signing will induce all the others to sign, but that none will sign if she does not, then her lost consumer surplus from signing is exactly $s(c)-s\left(p_{e}^{m}\right)$. All subsequent buyers have a smaller lost consumer surplus since even if all later buyers reject, the price will be elevated above $c$ due to the earlier buyers being covered. Thus, $s(c)-s\left(p_{e}^{m}\right)$ is an upper bound on the lost consumer surplus per buyer.

${ }^{23}(16)$ is increasing in $c_{e}$ at $c_{e}=c$, so satisfying this condition becomes harder as $c_{e}$ falls from $c$.
} 
$p_{e}=\operatorname{Min}\left\{p_{f}-d, p_{e}^{m}\right\}$ and sell to all buyers. Because the incumbent makes zero profit in the latter case, for any given fraction of covered buyers, $\theta$, the incumbent must choose a price $p_{f}$ such that the entrant prefers to sell only to uncovered buyers. That is, $p_{f}$ must satisfy:

$$
(1-\theta)\left(p_{f}-c_{e}\right) q(p)-\left(p_{f}-d-c_{e}\right) q\left(p_{f}-d\right) \geq 0
$$

Unlike when the entrant chooses price first, here the left hand side of (17) is decreasing in $\theta$, which means that the $p_{f}$ that satisfies (17) at equality is decreasing in $\theta$. Furthermore, notice that if (17) holds, covered buyers pay $p_{f}-d$ while uncovered buyers pay $\operatorname{Min}\left\{p_{f}, p_{e}^{m}\right\}$. Thus, unlike when the entrant prices first, here agreeing to be covered is a dominant strategy for buyers as long as one buyer will be covered. Whether or not the incumbent must pay to cover one buyer if all other buyers have rejected being covered depends on the pricing equilibrium with no covered buyers. With no covered buyers, the incumbent earns zero for any price $p_{f} \geq c$ and loses money on any lower price. Thus, there is no unique equilibrium with no covered buyers: buyers could face any price between $c$ and $p_{e}^{m}$ because the incumbent has zero sales and profits for any price in this region. ${ }^{24}$ It will be the most difficult for the incumbent to get buyers to agree to be covered by a loyalty discount if they believe the equilibrium with no covered buyers will result in a price of $c$. In that case, the incumbent would have to be willing to pay one buyer compensation. But, if buyers believe the incumbent will do that, then all buyers will agree to be covered for no compensation because they expect at least one covered buyer and they pay lower prices if they sign up both because covered buyers pay less than uncovered ones and because both prices are lower when there are more covered buyers.

Thus, the incumbent can certainly cover any fraction of buyers at no cost so long as it could profitably compensate one buyer for its lost consumer surplus (and possibly without needing to be able to profitably compensate any buyers). Ignoring the cost of compensating one buyer, the incumbent's profit from covering a fraction, $\theta$, of buyers is $\theta\left(p_{f}-d-c\right) q\left(p_{f}-d\right)$ where $p_{f}$ and $d$ must be such that (17) holds. If we assume there are no constraints on $d$, then

\footnotetext{
${ }^{24}$ We do not necessarily get the Bertrand equilibrium since (unlike with simultaneous pricing), the entrant will adjust its price based on the incumbent's to ensure the incumbent has zero sales for any price above $c$.
} 
we can restrict attention to $p_{f}=p_{e}^{m}$ and $p_{e}^{m}-d=p_{d \cdot}{ }^{25}$ (17) then implies that the highest discounted price the incumbent can charge is given by $\left(p_{d}-c_{e}\right) q\left(p_{d}\right)=(1-\theta)\left(p_{e}^{m}-c_{e}\right) q\left(p_{e}^{m}\right)$. With these substitutions, we totally differentiate (17) with respect to $\theta$ to obtain:

$$
\frac{d p_{d}}{d \theta}=-\frac{\left(p_{e}^{m}-c_{e}\right) q\left(p_{e}^{m}\right)}{q\left(p_{d}\right)-\left(p_{d}-c_{e}\right) q^{\prime}\left(p_{d}\right)}
$$

We then use this in differentiating the incumbent's profit to obtain the first order condition for $\theta$ :

$$
\theta=\frac{\left(p_{d}-c\right) q\left(p_{d}\right)\left\{q\left(p_{d}\right)-\left(p_{d}-c_{e}\right) q^{\prime}\left(p_{d}\right)\right\}}{\left(p_{e}^{m}-c_{e}\right) q\left(p_{e}^{m}\right)\left\{q\left(p_{d}\right)-\left(p_{d}-c\right) q^{\prime}\left(p_{d}\right)\right\}}
$$

The right hand side of (18) is increasing in $c_{e}$. At $c=c_{e}$, we get $\theta=\left(p_{d}-c\right) q\left(p_{d}\right) /\left(p_{e}^{m}-\right.$ c) $q\left(p_{e}^{m}\right)=1-\theta$, where the last equality follows from (17). This means that at $c=c_{e}$, the incumbent maximizes period 2 profits by covering half the buyers with loyalty discounts. If the entrant has a cost advantage, then the incumbent will cover a smaller fraction of the market with loyalty discounts. If the incumbent does have to be able to profitably compensate one buyer, it can do so at $c=c_{e}$ if $s(c)-s\left(p_{d}\right) \leq(N / 2)\left(p_{d}-c\right) q\left(p_{d}\right)$ where $p_{d}$ is given by $\left(p_{d}-c\right) q\left(p_{d}\right)=\left(p_{e}^{m}-c\right) q\left(p_{e}^{m}\right) / 2 .^{26}$ One might think that the incumbent would choose a larger $\theta$ because while that would reduce period 3 profits, it would reduce the amount of compensation required to ensure one buyer agrees to be covered. That isn't the case, however, because the incumbent does not have to actually pay this compensation. As long as it would be willing to compensate enough buyers, buyers will agree to be covered for no compensation because they expect the number of other buyers that will be covered will be such that uncovered buyers will pay $p_{e}^{m}$. Whereas, if they agree to be covered, they will pay $p_{d}<p_{e}^{m}$. We have now proved the following result.

Proposition 5 If the incumbent chooses price first, it will cover a fraction of buyers $\theta \leq 1 / 2$ by a loyalty discount without buyer commitment and covered buyers will agree to be

\footnotetext{
${ }^{25}$ The incumbent would never want to choose a discount that did not enable to entrant to capture all uncovered buyers at its monopoly price since that would simply force the incubment to choose a lower discounted price in order to ensure the entrant did not wish to compete for all buyers.

${ }^{26}$ This is the largest discounted price (if $c=c_{e}$ ) the incumbent can charge for which the entrant weakly prefers to sell to half the buyers at its monopoly price than to sell to all the buyers at the incumbent's discounted price.
} 
covered for no compensation if $s(c)-s\left(p_{d}\right) \leq \theta N\left(p_{d}-c\right) q\left(p_{d}\right)$ where $p_{d}$ is given by $\left(p_{d}-c_{e}\right) q\left(p_{d}\right)=(1-\theta)\left(p_{e}^{m}-c_{e}\right) q\left(p_{e}^{m}\right)$. The fraction of buyers that will be covered is increasing in $c_{e}$ and is $1 / 2$ at $c_{e}=c$. Covered buyers will pay $p_{d}$, which is strictly greater than $c$ but strictly less than $p_{e}^{m}$. Uncovered buyers will pay $p_{e}^{m}$.

Thus, if the incumbent chooses price first, then it can use loyalty discounts without buyer commitment to ensure that it makes positive profits and continues to serve a fraction of the market despite its higher costs. Whether consumer's pay higher prices or not depends on what the equilibrium outcome is absent loyalty discounts, which is uncertain given that there is a continuum of equilibria.

\subsection{Simultaneous Pricing}

We now consider the case of in which the entrant and incumbent choose their prices simultaneously in period 2. It turns out that this case has a great deal in common with the case in which the incumbent chooses price first.

As was the true in the commitment case, the pricing equilibrium here must be in mixed strategies. To see this, imagine that the entrant chose a price $p_{e}$. Then the incumbent would choose a discounted price $(p-d)$ just below $p_{e}$ in order to sell to covered buyers. The entrant's best response to such a price, however, would be either to match it or choose $p_{e}^{m}$ and sell only to uncovered buyers. Because the entrant's best response to a price just below $p_{e}^{m}$ would be to match it, there can be no pure strategy equilibrium.

We first assume that the discount, $d$, is large enough that the incumbent cannot profitably compete for buyers who did not accept the loyalty discount (uncovered buyers), even if the entrant prices at its monopoly level. We establish that this is optimal for the incumbent in the appendix. To determine the mixed strategy equilibrium, notice that if the entrant's price distribution is given by the cumulative distribution function $F_{e}$, then the incumbent's expected period 2 profit from a discounted price of $p_{d}$ is $\theta\left(1-F_{e}\left(p_{d}\right)\right)\left(p_{d}-c\right) q\left(p_{d}\right)$. We know that the entrant will never charge a price that exceeds $p_{e}^{m}$, nor will it ever charge a price lower than $p_{0}$ where $p_{0}$ solves $\left(p_{0}-c_{e}\right) q\left(p_{0}\right)=(1-\theta)\left(p_{e}^{m}-c_{e}\right) q\left(p_{e}^{m}\right)$ because the entrant can 
always earn $(1-\theta)\left(p_{e}^{m}-c_{e}\right) q\left(p_{e}^{m}\right)$ from selling only to uncovered buyers. ${ }^{27}$ Thus, $F_{e}$ must be such that the incumbent can earn the same profit from charging $p_{d}=p_{0}$ and selling to covered buyers with probability one or charging some other $p_{d}$ and selling to covered buyers with probability $1-F_{e}\left(p_{d}\right)$. That is:

$$
\theta\left(1-F_{e}\left(p_{d}\right)\right)\left(p_{d}-c\right) q\left(p_{d}\right)=\theta\left(p_{0}-c\right) q\left(p_{0}\right)
$$

This implies that

$$
F_{e}\left(p_{d}\right)=1-\frac{\left(p_{0}-c\right) q\left(p_{0}\right)}{\left(p_{d}-c\right) q\left(p_{d}\right)}
$$

with an atom at $p_{e}^{m}$ of $\frac{\left(p_{0}-c\right) q\left(p_{0}\right)}{\left(p_{e}^{m}-c\right) q\left(p_{e}^{m}\right)}$.

If the incumbent's pricing distribution is given by the cumulative distribution function $F$, then the entrant's expected profit from charging a price of $p_{e}$ is $\theta\left(1-F\left(p_{e}\right)\right)\left(p_{e}-c_{e}\right) q\left(p_{e}\right)+$ $(1-\theta)\left(p_{e}-c_{e}\right) q\left(p_{e}\right)$. The entrant sells to all uncovered buyers as long as the discount is large enough that the incumbent's undiscounted price exceeds $p_{e}^{m}$, which the Appendix proves is always the case. The entrant sells to covered buyers with probability $1-F\left(p_{e}\right)$. The entrant can always choose a price of $p_{e}^{m}$ and obtain profits of $(1-\theta)\left(p_{e}^{m}-c_{e}\right) q\left(p_{e}^{m}\right)$ by only selling to uncovered buyers. ${ }^{28}$ That is:

$$
\theta\left(1-F\left(p_{e}\right)\right)\left(p_{e}-c_{e}\right) q\left(p_{e}\right)+(1-\theta)\left(p_{e}-c_{e}\right) q\left(p_{e}\right)=(1-\theta)\left(p_{e}^{m}-c_{e}\right) q\left(p_{e}^{m}\right)
$$

This implies that

$$
F\left(p_{e}\right)=\frac{\left(p_{e}-c_{e}\right) q\left(p_{e}\right)-(1-\theta)\left(p_{e}^{m}-c_{e}\right) q\left(p_{e}^{m}\right)}{\theta\left(p_{e}-c_{e}\right) q\left(p_{e}\right)}
$$

Notice that the $p_{0}$, the minimum of both price distributions, is decreasing in $\theta$ (the condition for $p_{0}$ implies that $\left.d p_{0} / d \theta=-\left(p_{e}^{m}-c_{e}\right) q\left(p_{e}^{m}\right) /\left\{q\left(p_{0}\right)+\left(p_{0}-c_{e}\right) q^{\prime}\left(p_{0}\right)\right\}\right) ; F_{e}\left(p_{d}\right)$ is decreasing in $p_{0}$ (and the atom at $p_{e}^{m}$ is increasing in $p_{0}$ ); and $F\left(p_{e}\right)$ is increasing in $\theta$. This

\footnotetext{
${ }^{27}$ Since $p_{0} \geq c$, this creates a maximum $\theta$ for the mixed strategy equilibrium. For any $\theta$ above this maximum, the entrant will charge $c$ with probability one. Obviously, any $\theta$ above this maximum will not be in the interest of the incumbent, since it will earn zero profits. The maximum $\theta=1-\frac{\left(c-c_{e}\right) q(c)}{\left(p_{e}^{m}-c_{e}\right) q\left(p_{e}^{m}\right)}$.

${ }^{28}$ In equilibrium, the incumbent's maximum price cannot exceed the entrant's maximum price or the incumbent would make no profits. Thus, the entrant only sells to uncovered buyers at its maximum price. Given this, the entrant's maximum price must be $p_{e}^{m}$.
} 
means that the larger the fraction of covered buyers, the lower the prices (in expectation) that buyers will face from both the entrant and the incumbent. Thus, once one buyer is covered, other buyers strictly prefer to be covered than uncovered. Hence, as was the case when the incumbent chose price first, the incumbent need only be able to profitably compensate one buyer in order to induce as many buyers as it wants to be covered. In this case, however, the unique equilibrium with no covered buyers is the competitive one, so there is no doubt about the fact that the incumbent must be able to profitably compensate one buyer.

Once again, then, we simply need to determine the fraction of covered buyers that maximizes the incumbent's profits given the pricing distributions. The incumbent's expected profit is simply $\theta\left(p_{0}-c\right) q\left(p_{0}\right)$ (because he can charge $p_{0}$ and sell to all covered buyers with probability one). Using the expression for $d p_{0} / d \theta$ in the last paragraph, the first order condition for $\theta$ is:

$$
\theta=\frac{\left(p_{0}-c\right) q\left(p_{0}\right)\left\{q\left(p_{0}\right)+\left(p_{0}-c_{e}\right) q^{\prime}\left(p_{0}\right)\right\}}{\left(p_{e}^{m}-c_{e}\right) q\left(p_{e}^{m}\right)\left\{q\left(p_{0}\right)+\left(p_{0}-c\right) q^{\prime}\left(p_{0}\right)\right\}}
$$

Notice, this is the exact same condition for $\theta$ as when the incumbent chose price first (see equation (18)) with $p_{d}$ replaced by $p_{0}$. But, also notice the condition for $p_{0}$ here is identical for the condition for $p_{d}$ in the last subsection. Hence, the optimal fraction of buyers that the incumbent will choose to cover is identical (it will be exactly half if $c=c_{e}$ and less than half if the entrant has a cost advantage). The only difference between the equilibria in the two cases is that (i) the incumbent's price is higher in the simultaneous pricing case because instead of charging $p_{d}=p_{0}$ with probability one, he charges price drawn from a distribution between $p_{0}$ and $p_{e}^{m}$; and (ii) the entrant's price is lower because instead of charging $p_{e}^{m}$ with probability one, it charges a price drawn from a distribution between $p_{0}$ and $p_{e}^{m}$. Thus, uncovered buyers are better off under simultaneous pricing but covered buyers are worse off relative to the case in which the incumbent chooses price first.

Given that the incumbent's period 2 profits are identical in the two cases as is the fraction of covered buyers, we have proven the following result.

Proposition 6 If the incumbent and entrant choose price simultaneously, the incumbent will cover a fraction of buyers $\theta \leq 1 / 2$ by a loyalty discount without buyer commitment 
and covered buyers will agree to be covered for no compensation if $s(c)-s\left(p_{0}\right) \leq$ $\theta N\left(p_{0}-c\right) q\left(p_{0}\right)$ where $p_{0}$ is given by $\left(p_{0}-c_{e}\right) q\left(p_{0}\right)=(1-\theta)\left(p_{e}^{m}-c_{e}\right) q\left(p_{e}^{m}\right)$. The fraction of buyers that will be covered is increasing in $c_{e}$ and is $1 / 2$ at $c_{e}=c$. Both covered and uncovered buyers will pay a price between $p_{0}$ and $p_{e}^{m}$.

This proposition establishes that with simultaneous pricing, the incumbent can use loyalty discounts without buyer commitment to prevent the entrant from capturing the entire market, leading both to production inefficiency and prices that are elevated above the competitive level along with the associated allocation inefficiency. In fact, as we have seen, we get similar results no matter what the period 2 pricing game is. While, without buyer commitment, loyalty discounts cannot exclude the entrant from the entire market, they can ensure that the incumbent retains positive market share (despite its relative inefficiency) and maintain supra-competitive prices.

The above proposition assumes that the incumbent has chosen a large enough discount that, in equilibrium, even if the entrant charges its monopoly price, it will sell to all uncovered buyers. We show in the appendix that the incumbent will not choose a smaller discount that does not satisfy that property. We do this by showing that, with any discount that does not satisfy that property, there exists an equilibrium in which the incumbent earns lower profits.

\section{Conclusion}

This article has shown that loyalty discounts (which involve seller commitments to charge loyal buyers less than disloyal buyers) can increase prices and/or block entry. Strikingly, this result is possible under any demand curve, even if the entrant is more efficient than the incumbent,and without any entry costs or economies of scale, and even if the buyers are final consumers (or otherwise have independent demand). It can also occur with or without buyer commitment. With buyer commitment, unless the entrant cost advantage is sufficiently large, this equilibrium will always occur for a sufficient number of buyers. With linear demand, and an entrant cost advantage of less than 10\%, an incumbent can profitably foreclose the entire market with as few as three buyers unless incumbent costs are more than

$28 \%$ of the choke price. Not only are prices raised but a more efficient rival is kept off the 
market. Without buyer commitment, the rival will not be kept off the market entirely, but supracompetitive pricing will result as long as the entrant's cost advantage is not too great.

These results show that the intuition that loyalty discounts presumptively reduce prices is misplaced. Loyalty "discounts" are just the difference between loyal and disloyal pricing, and thus need not signify any true discount from the but-for prices that would have existed but for the loyalty discounts. In fact, this model shows that loyalty discounts encourage incumbents to raise prices above but for levels and discourage discounting to free buyers. These results also disprove the intuition that above-cost loyalty discounts cannot exclude an equally efficient rival. Here, above-cost loyalty discounts can exclude the rival even though the rival is in fact more efficient than the incumbent. Further, it can do so even though there are no economies of scale that might mean the rival has been relegated to a high cost portion of its cost curve. These results also disprove the claim that voluntary buyer agreement means the agreement must enhance the welfare of buyers. In fact, we show that loyalty discounts (either with or without commitment) can have anti-competitive effects even if buyers can coordinate on their preferred equilibrium.

Our results have important implications for competition policy. Antitrust enforcers should scrutinize loyalty discounts with buyer commitment in situations in which ordinary exclusive dealing might not be of concern (independent buyers, no economies of scale). Antitrust enforcers should not view loyalty discounts more favorably if buyer coordination is likely; it does not eliminate the potential for anti-competitive effects from loyalty discounts. Loyalty discounts without buyer commitment can also have anti-competitive effects, even though they are not likely to be completely exclusionary and may sometimes even increase the entrant's profits. In addition, antitrust enforcers should not take the fact that only a minority of buyers are covered by loyalty discounts as evidence that it is not having an anticompetitive effect. Loyalty discounts with buyer commitment can have anticompetitive effects even when they cover a minority of the market, and for loyalty discounts without commitment, covering a minority of buyers is part the incumbent's optimal anticompetitive strategy.

Our model assumes that the incumbent only offers a discount off a price to be determined later. We explained above, in footnote 10, why specifying price in advance might not be 
possible (this is the standard assumption in the exclusive dealing literature). That said, if the incumbent could offer a contract that specified price in advance, this would not be as profitable for the incumbent unless the contract somehow linked the price it offered to loyal buyers to the price if offered to disloyal buyers. It is this linking of price that creates the externality across buyers that allows the incumbent to retain market share and earn profits even though this reduces total welfare. If the incumbent could credibly commit to a price to both loyal buyers and disloyal buyers, then it could effectively deter entry and capture most of the consumer surplus. It would do this by commiting to charge disloyal buyers a price above the entrant's monopoly price and charging loyal buyers its marginal cost in exchange for a payment of $s(c)-s\left(p_{e}^{m}\right)$. However, such a commitment, even if in a contract, might not be credible, if buyers are independent, because breaching the seller commitment to charge disloyal buyers a high price would not create any damages for anyone.

A few limitations should, however, be stressed. First, we have assumed a market with only one potential rival. This can often be the case, especially in high-tech or pharmaceutical markets, but if there were multiple rivals with similar costs it is possible they would compete prices down to their costs. However, the same sort of analysis seems likely to apply to the extent only one entrant has a potential cost advantage and the other rivals have higher costs and merely provide a competitive fringe. Multiple rivals might also use loyalty discounts themselves, creating similar or even exacerbated market segmentation effects. ${ }^{29}$ But it remains for future work to extend the model here to cases involving multiple rivals or where multiple firms use loyalty discounts. ${ }^{30}$

Second, when analyzing loyalty discounts with buyer commitments, we have assumed that buyers always honor their commitments. The analysis would get more complicated if we considered the possibility that buyers could freely breach their commitments. However, as we have discussed above, if buyers must pay damages for breach of contract when they breach their loyalty commitments, then this would often deter breach, and even if it does not, it does not eliminate the ability of the incumbent to profitably use loyalty discount contracts to reduce competition. ${ }^{31}$ Moreover, as Elhauge (2009) has pointed out, there may

\footnotetext{
${ }^{29}$ See Elhauge (2009) at pp. 195, 214-15 for a discussion of these issues.

${ }^{30}$ See Kitamura (2010) for an argument that naked exclusion is less effective if there are multiple entrants.

${ }^{31}$ Note that Elhauge (2009) finds that, under linear demand, loyalty commitments will induce rivals to
} 
be many reasons why the legal or extralegal penalties for breach exceed expectation damages. Further, we find that loyalty discounts can have anticompetitive effects without any buyer commitments.

Lastly, we have assumed loyalty discounts have no efficiencies. If they did, those might offset any adverse effects. It seems likely the present model can be extended to show how much of a cost reduction would be necessary to offset the anticompetitive effects, but that also remains a matter for future work.

\section{Appendix}

Proof of Proposition 1. (i) Inspection of (4) makes it clear that it does not depend on $c_{e}$. Because increasing $c_{e}$ increases $p_{e}^{m}$, however, the atom in the entrant's distribution at $p_{e}^{m}$ is now spread out between $\left[p_{e}^{m}, p_{e}^{\prime m}\right] . \quad p_{0}$ is also not affected by $c_{e}$ (see (5)). Differentiating (8) with respect to $c_{e}$ gives $\frac{\left(p-p_{0}\right) q\left(p_{0}\right)}{\left(p-c_{e}\right)^{2} q(p)}>0$. Thus, for any $p<p_{e}^{m}$, the probability that the incumbent charges a price less than $p$ is increasing in $c_{e}$ for $p<p_{e}^{m}$. There is a new atom at $p_{e}^{\prime m}$ and positive probability up to $p_{e}^{\prime m}$. (ii) Differentiating (6) with respect to $c$ gives $-\theta \frac{\left(p^{m}-p\right) q\left(p^{m}\right)+d q(p-d)+\left(d p^{m} / d c\right)\left[q\left(p^{m}\right)+\left(p^{m}-c\right) q^{\prime}\left(p^{m}\right)\right]}{(1-\theta)(p-c)^{2} q(p)}<0$. This is negative because the term in square brackets in the numerator is zero because $p^{m}$ maximizes profits and $p^{m}>p$ and $d>0$. $c$ only affects the incumbent's pricing distribution, (9), through its effect on $p_{0}$. Because $p_{0}<p^{m}$, increasing $p_{0}$ decreases $F(p)$ for any $p<p_{e}^{m}$. Totally differentiating (5) with respect to $c$ and solving for $\frac{d p_{0}}{d c}$ gives $\frac{d p_{0}}{d c}=\frac{(1-\theta) q\left(p_{0}\right)+\theta\left(q\left(p_{0}-d\right)-q\left(p^{m}\right)\right)+\theta\left(d p^{m} / d c\right)\left[q\left(p^{m}\right)+\left(p^{m}-c\right) q^{\prime}\left(p^{m}\right)\right]}{(1-\theta)\left[q\left(p_{0}\right)+\left(p_{0}-c\right) q^{\prime}\left(p_{0}\right)\right]+\theta\left[q\left(p_{0}-d\right)+\left(p_{0}-d-c\right) q^{\prime}\left(p_{0}-d\right)\right]}>0$. This is positive because $p_{0}<p^{m}, d>0$, and $q\left(p^{m}\right)+\left(p^{m}-c\right) q^{\prime}\left(p^{m}\right)=0$. So, increasing $c$ increases $p_{0}$ which reduces $F(p)$ for any $p<p_{e}^{m}$. (iii) $\theta$ only affects the incumbent's pricing through its effect on $p_{0}$. Totally differentiating (5) with respect to $\theta$ and solving for $\frac{d p_{0}}{d \theta}$ gives $\frac{d p_{0}}{d \theta}=\frac{\left(p_{0}-c\right) q\left(p_{0}\right)+\left(p^{m}-c\right) q\left(p^{m}\right)-\left(p_{0}-d-c\right) q\left(p_{0}-d\right)}{(1-\theta)\left[q\left(p_{0}\right)+\left(p_{0}-c\right) q^{\prime}\left(p_{0}\right)\right]+\theta\left[q\left(p_{0}-d\right)+\left(p_{0}-d-c\right) q^{\prime}\left(p_{0}-d\right)\right]}>0$. So, increasing $\theta$ increases $p_{0}$ which reduces $F(p)$ for any $p<p_{e}^{m}$. Differentiating (6) with respect to $\theta$ gives $-\theta \frac{\left(p^{m}-c\right) q\left(p^{m}\right)-(p-d-c) q(p-d)}{(1-\theta)(p-c)^{2} q(p)}<0$. So, increasing $\theta$ reduces the probability that the entrant chooses a price below any given level $p<p_{e}^{m}$. (iv) $d$ only affects the incumbent's pricing through $p_{0}$. Totally differentiating (5) with respect to $d$ and solving

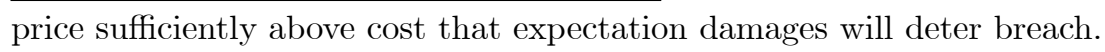


for $\frac{d p_{0}}{d d}$ gives $\frac{d p_{0}}{d d}=\frac{\theta\left[q\left(p_{0}-d\right)+\left(p_{0}-d-c\right) q^{\prime}\left(p_{0}-d\right)\right]}{(1-\theta)\left[q\left(p_{0}\right)+\left(p_{0}-c\right) q^{\prime}\left(p_{0}\right)\right]+\theta\left[q\left(p_{0}-d\right)+\left(p_{0}-d-c\right) q^{\prime}\left(p_{0}-d\right)\right]}>0$. So, increasing $d$ increases $p_{0}$ which reduces $F(p)$ for any $p<p_{e}^{m}$. Differentiating (6) with respect to $d$ gives $-\theta \frac{q(p-d)+(p-d-c) q^{\prime}(p-d)}{(1-\theta)(p-c) q(p)}<0$. So, increasing $d$ reduces the probability that the entrant chooses a price below any given level $p<p_{e}^{m}$. Q.E.D.

\section{Linear Demand Numerical Analysis}

Solving (5) explicitly for $p_{0}$ gives $p_{0}(\theta)=\left\{(1+c+2 d \theta)-\sqrt{(1-\theta)\left((1-c)^{2}-4 d \theta\right)}\right\} / 2$. The expected consumer surplus for both committed and free buyers as a function of the number of committed buyers, $n$, is given by:

$$
\begin{aligned}
E s^{c}(n)= & \int_{p_{0}(n)}^{\left(1+c_{E}\right) / 2} \frac{1}{2}(1-p-d)^{2} \frac{\left(1+c_{E}-2 p\right)\left(1-p_{0}(n)\right)\left(p_{0}(n)-c_{E}\right)}{(1-p)^{2}\left(p-c_{E}\right)^{2}} d p+ \\
& \frac{4\left(1-p_{0}(n)\right)\left(p_{0}(n)-c_{E}\right)}{\left(1-c_{E}\right)^{2}}(1-c)^{2} / 8
\end{aligned}
$$

$$
\begin{aligned}
E s^{f}(n)= & \int_{p_{0}(n)}^{\left(1+c_{E}\right) / 2} \frac{1}{2}(1-p)^{2} \frac{(n / N)(1+c-2(p-d))^{2}}{4(1-p)(p-c)(1-(n / N))} \frac{\left(1+c_{E}-2 p\right)\left(1-p_{0}(n)\right)\left(p_{0}(n)-c_{E}\right)}{(1-p)^{2}\left(p-c_{E}\right)^{2}} d p+ \\
& \int_{p_{0}(n)}^{\frac{\left(a+c_{E}\right)}{2}} \frac{1}{2}(1-p)^{2} \frac{\left(1-p_{0}(n)\right)\left(p_{0}(n)-c_{E}\right)}{(1-p)\left(p-c_{E}\right)} \frac{n(1+c-2(p-d))\left((1-c)^{2}+2 d(1+c-2 p)\right)}{4 N(1-(n / N))(1-p)^{2}(p-c)^{2}} d p+ \\
& \frac{4\left(1-p_{0}(n)\right)\left(p_{0}(n)-c_{E}\right)}{\left(1-c_{E}\right)^{2}} \frac{(n / N)\left(c-c_{E}+2 d\right)}{(1-(n / N))\left(1-c_{E}\right)\left(1-2 c+c_{E}\right)}\left(1-c_{E}\right)^{2} / 8
\end{aligned}
$$

In these expressions, $p_{0}(n)$ is simply $p_{0}(\theta)$ with $\theta=n / N$. The first expression is the expected surplus for committed buyers when $n$ buyers will be committed. The integral term is the expected surplus when the incumbent prices between $p_{0}$ and $p_{e}^{m}$. For any given price, a committed buyer's surplus is $\frac{1}{2}(1-p-d)^{2}$ (because she gets the discount of $d$ off the price of $p$ offered to free buyers). The incumbent's probability density function in this region is $\frac{\left(1+c_{E}-2 p\right)\left(1-p_{0}(n)\right)\left(p_{0}(n)-c_{E}\right)}{(1-p)^{2}\left(p-c_{E}\right)^{2}}$. This can be computed simply by differentiating the incumbent's cumulative distribution function, equation (9), under the linear demand assumption. The incumbent will also charge committed buyers the monopoly price with probability $\frac{4\left(1-p_{0}(n)\right)\left(p_{0}(n)-c_{E}\right)}{\left(1-c_{E}\right)^{2}}$ and when that happens these buyers obtain a surplus of $(1-$ $c)^{2} / 8$.

The second expression is the surplus for free buyers. This contains three terms. The 
first two reflect the expected surplus when neither $I$ nor $E$ charge their monopoly prices. The first is the expected surplus the buyer gets when buying from the incumbent, which occurs when the entrant's price is higher. For any given incumbent price $p$, the probability of this is $\frac{(n / N)(1+c-2(p-d))^{2}}{4(1-p)(p-c)(1-(n / N))}$. This is simply $1-F_{e}(p)$ with linear demand. The second term is the expected surplus the buyer gets when buying from the entrant, which occurs when the incumbent's price is higher. For any given entrant price $p$, the probability of this is $\frac{\left(1-p_{0}(n)\right)\left(p_{0}(n)-c_{E}\right)}{(1-p)\left(p-c_{E}\right)}$. Again, this is $1-F(p)$ with linear demand. The last part of this term is entrant's probability density function in this region with linear demand. The last term is the expected surplus if both $I$ and $E$ charge their monopoly prices. The first expressions in this last line are the probability that this occurs, the $\left(1-c_{E}\right)^{2} / 8$ expression is the buyer's surplus in this case (because the buyer buys from the entrant because $c_{E} \leq c$ ).

\section{Proof that large discount is optimal in section 3.3}

Next, we show that in the simultaneous pricing case without commitment, that the incumbent will choose a large enough discount so that it will not sell to uncovered buyers in equilibrium. First, note that if $\left(c-c_{e}\right) q(c) \geq(1-\theta)\left(c+d-c_{e}\right) q(c+d)$, then there exists a pure strategy equilibrium in which $p_{e}=p_{d}=c$ and the entrant captures the entire market. Such an equilibrium is obviously less profitable to the incumbent than the large $d$ equilibrium. This equilibrium exists when $d$ is very small.

The large $d$ equilibrium described above requires that the incumbent does not want to deviate by choosing a discounted price of $p_{e}^{m}-d$ in order to sell to uncovered buyers at $p_{e}^{m}$ in the event that the entrant charges $p_{e}^{m}$ (and to all covered buyers with probability one at $\left.p_{e}^{m}-d\right)$. This deviation is not profitable if and only if:

$$
(2 \theta-1)\left(p_{0}-c\right) q\left(p_{0}\right)-\theta\left(p_{e}^{m}-d-c\right) q\left(p_{e}^{m}-d\right) \geq 0
$$

because $\theta \leq 1 / 2$, this equilibrium requires that $d>p_{e}^{m}-c$.

It is easy to see that there may exist an intermediate $d$ such that neither of these two equilbria exist. For example, if $c=c_{e}$, the pure strategy equilibrium does not exist for any $d>0$ and yet the large $d$ mixed strategy equilibrium will not exist for $d<p_{e}^{m}-c$. In this intermediate case, we construct a mixed strategy equilibrium of the same type as 
the equilibrium with a large discount. The key difference is that the top price charged with positive probability, which we will call $p_{T}$, and the bottom price charged, $p_{B}$, must be smaller to satisfy the no deviation condition. $p_{T}$ and $p_{B}$ still satisfy $\left(p_{B}-c_{e}\right) q\left(p_{B}\right)=$ $(1-\theta)\left(p_{T}-c_{e}\right) q\left(p_{T}\right)$, so that the entrant is indifferent between selling only to uncovered buyers (with probability one) at $p_{T}$ and selling to all buyers (with probability one) at $p_{B} \cdot{ }^{32}$ The entrant's price distribution is given by $F_{e}\left(p_{d}\right)=1-\frac{\left(p_{B}-c\right) q\left(p_{B}\right)}{\left(p_{d}-c\right) q\left(p_{d}\right)}$ with an atom at $p_{T}$ of $\frac{\left(p_{0}-c\right) q\left(p_{0}\right)}{\left(p_{T}-c\right) q\left(p_{T}\right)}$. The incumbent's distribution is given by $F\left(p_{e}\right)=\frac{\left(p_{e}-c_{e}\right) q\left(p_{e}\right)-(1-\theta)\left(p_{T}-c_{e}\right) q\left(p_{T}\right)}{\theta\left(p_{e}-c_{e}\right) q\left(p_{e}\right)}$. The analysis above shows that these distributions guarantee that both the incumbent and the entrant are indifferent between charging any (discounted for the incumbent) price in the interval between $p_{B}$ and $p_{T}$.

When the discount is small, however, it remains to show that the incumbent does not want to deviate to a discounted price of $p_{T}-d$ in order to sell to uncovered buyers at $p_{T}$ in the event that the entrant charges $p_{T}$ (and to all covered buyers with probability one at $\left.p_{T}-d\right)$. The incumbent's expected profit from charging a discounted price of $p_{T}-d$ :

$$
(1-\theta) \frac{\left(p_{B}-c\right) q\left(p_{B}\right)}{\left(p_{T}-c\right) q\left(p_{T}\right)}\left(p_{T}-c\right) q\left(p_{T}\right)+\theta\left(p_{T}-d-c\right) q\left(p_{T}-d\right)
$$

This deviation is not profitable if and only if:

$$
(2 \theta-1)\left(p_{B}-c\right) q\left(p_{B}\right)-\theta\left(p_{T}-d-c\right) q\left(p_{T}-d\right) \geq 0
$$

If $\theta<1 / 2$, it is easiest to deter deviation with $p_{B}=c$. In that case, deviation is not profitable if and only if $p_{T} \leq c+d$. If this does not hold, then thee equilibrium in which $p_{e}=p_{d}=c$ and the entrant captures the entire market exists. So, whenever this equilibrium does not exist, we can deter deviation from this mixed strategy equilibrium by choosing $p_{B}=c$ and $p_{T}$ given by $\left(c-c_{e}\right) q\left(p_{B}\right)=(1-\theta)\left(p_{T}-c_{e}\right) q\left(p_{T}\right)$. While this equilibrium may also exist (it may be possible to deter deviation) for $p_{B}>c$, we must have $p_{B}<p_{0}$ and $p_{T}<p_{e}^{m}$ or else we are in the large $d$ equilibrium. As a result, this equilibrium is less

\footnotetext{
${ }^{32}$ Once again, since $p_{B} \geq c$, this creates a maximum $\theta$ for this mixed strategy equilibrium. For any $\theta$ above this maximum, the entrant will charge $c$ with probability one. The maximum $\theta=1-\frac{\left(c-c_{e}\right) q(c)}{\left(p_{T}-c_{e}\right) q\left(p_{T}\right)}$. Clearly, this maximum is smaller than the above maximum with large $d$ since $p_{T}<p_{e}^{m}$.
} 
profitable for the incumbent than the large $d$ equilibrium.

It is worth pointing out that the equilibrium in this case is different from the equilibrium described in Elhauge (2009) for simultaneous pricing without commitment and a small discount. In Elhauge's proposed equilibrium, the incumbent could profitably deviate by charging a discounted price just below the support of his distribution that allows him to sell to uncovered buyers with non-zero probability because the entrant has an atom in its distribution at its highest price.

\section{References}

[1] Aghion, Philippe, and Patrick Bolton. 1987. "Contracts as a Barrier to Entry." American Economic Review, 77(3): 388-401.

[2] Argention, Cedric. 2010. "Exclusive Quality." Journal of Industrial Economics, 58:690716.

[3] Bernheim, B. Douglas, and Michael D. Whinston. 1998. "Exclusive Dealing." Journal of Political Economy, 106(1): 64-103.

[4] Butz, David A. 1990. "Durable-Good Monopoly and Best-Price Provisions," American Economic Review 80: 1062-76.

[5] Chen, Zhijun and Greg Shaffer. 2010. "Naked Exclusion with Minimum Share Requirements," Working Paper.

[6] Cooper, Thomas E. 1986. "Most-Favored-Customer Pricing and Tacit Collusion," The RAND Journal of Economics 17: 377-388.

[7] Edlin, Aaron. 1997. "Do Guaranteed-Low-Price Policies Guarantee High Prices, and Can Antitrust Rise to the Challenge?", Harvard Law Review 111: 528-575.

[8] Elhauge, Einer. 2003. "Defining Better Monopolization Standards." Stanford Law Review 56: 253-344. 
[9] Elhauge, Einer. 2008. United States Antitrust Law \& Economics. Foundation Press: New York.

[10] Elhauge, Einer. 2009. "How Loyalty Discounts Can Perversely Discourage Discounting," Journal of Competition Law \& Economics 5: 189-231.

[11] Farrell, Joseph. 2005. "Deconstructing Chicago on Exclusive Dealing," Antitrust Bulletin 50: 465-480 (2005).

[12] Fumagalli, Chiara, and Massimo Motta. 2006. "Exclusive Dealing and Entry, when Buyers Compete." American Economic Review, 96(3):785-95.

[13] Hovenkamp, Herbert. 2005. Antitrust Law Vol.. XI (2d ed.).

[14] Hovenkamp, Herbert. 2006. "Discounts and Exclusion." Utah Law Review, 2006: 841861.

[15] Hviid, Morten and Greg Shaffer. 2010. "Matching Own Prices, Rivals' Prices or Both?" Journal of Industrial Economics, 58:479-506.

[16] Innes, Robert, and Richard J. Sexton. 1994. "Strategic Buyers and Exclusionary Contracts." American Economic Review, 84(3): 566-84.

[17] Kaplow, Louis \& Carl Shapiro. 2007. "Antitrust," in Handbook of Law \& Economics 2: 1073-1225 (eds. Polinsky \& Shavell).

[18] Kitamura, Hiroshi. 2010. "Exclusionary Vertical Contracts with Multiple Entrants." International Journal of Industrial Organization, 28:213-219.

[19] Kolay, Sreya, Greg Shaffer, and Janusz A. Ordover. 2004. "All-Units Discounts in Retail Contracts," Journal of Economics and Management Strategy, 13:429-459.

[20] Lambert, Thomas A.. 2005. "Evaluating Bundled Discounts." Minnesota Law Review, 89: $1688-1757$.

[21] Lin, Y. Joseph. 1990. "The Dampening of Competition Effect of Exclusive Dealing," Journal of Industrial Economics, 39:209-223. 
[22] Mahenc, Philippe and Francois Salanie. 2004. "Softening Competition Through Forward Trading," Journal of Economic Theory, 116:282-293.

[23] Marx, Leslie M. \& Greg Shaffer. 2004. "Opportunism in Multilateral Vertical Contracting: Nondiscrimination, Exclusivity, and Uniformity: Comment," American Economic Review 94: 796-801.

[24] Marx, Leslie M. \& Greg Shaffer. 2004. "Rent-Shifting, Exclusion, and Market-Share Discounts," Working Paper.

[25] Mathewson, G. Frank, and Ralph A. Winter. 1987. "The Competitive Effects of Vertical Agreements: Comment." American Economic Review, 77(5): 1057-62.

[26] Neeman, Zvika. 1999. "The Freedom to Contract and the Free-Rider Problem." Journal of Law, Economics, and Organization, 15(3): 685-703.

[27] Ordover, Janusz and Greg Shaffer. 2007. "Exclusionary Discounts," Working Paper.

[28] Rasmusen, Eric B., J. Mark Ramseyer, J., and John S, Wiley. 1991. "Naked Exclusion", American Economic Review, 81(5):1137-45.

[29] Rey, Patrick and Joseph E. Stiglitz. 1995. "The Role of Exclusive Territories in Producers' Competition," The RAND Journal of Economics 26: 431-451.

[30] Schnitzer, Monika. 1994. "Dynamic duopoly with best-price clauses," The RAND Journal of Economics 25: 186-196.

[31] Segal, Ilya R., and Michael Whinston. 2000. "Naked Exclusion: Comment." American Economic Review, 90: 296-309.

[32] Simpson, John and Abraham L. Wickelgren. 2007. "Naked Exclusion, Efficient Breach, and Downstream Competition." American Economic Review, 97: 1305-1320.

[33] Spector, David. 2005. "Loyalty Rebates: An Assessment of Competition Concerns and a Proposed Structured Rule of Reason," Competition Policy International 1(2): 89-114 (Autumn). 
[34] Tom, Willard K., David A. Balto \& Neil W. Averitt. 2000. "Anticompetitive Aspects of Market-Share Discounts and Other Incentives to Exclusive Dealing," Antitrust L.J. 67: 615 .

[35] Whinston, Michael D. 2006. Lectures on Antitrust Economics (2006).

[36] Wright, Julian. 2008. "Naked Exclusion and the Anticompetitive Accomodation of Entry," Economics Letters, 98:107-112. 
Figure 1

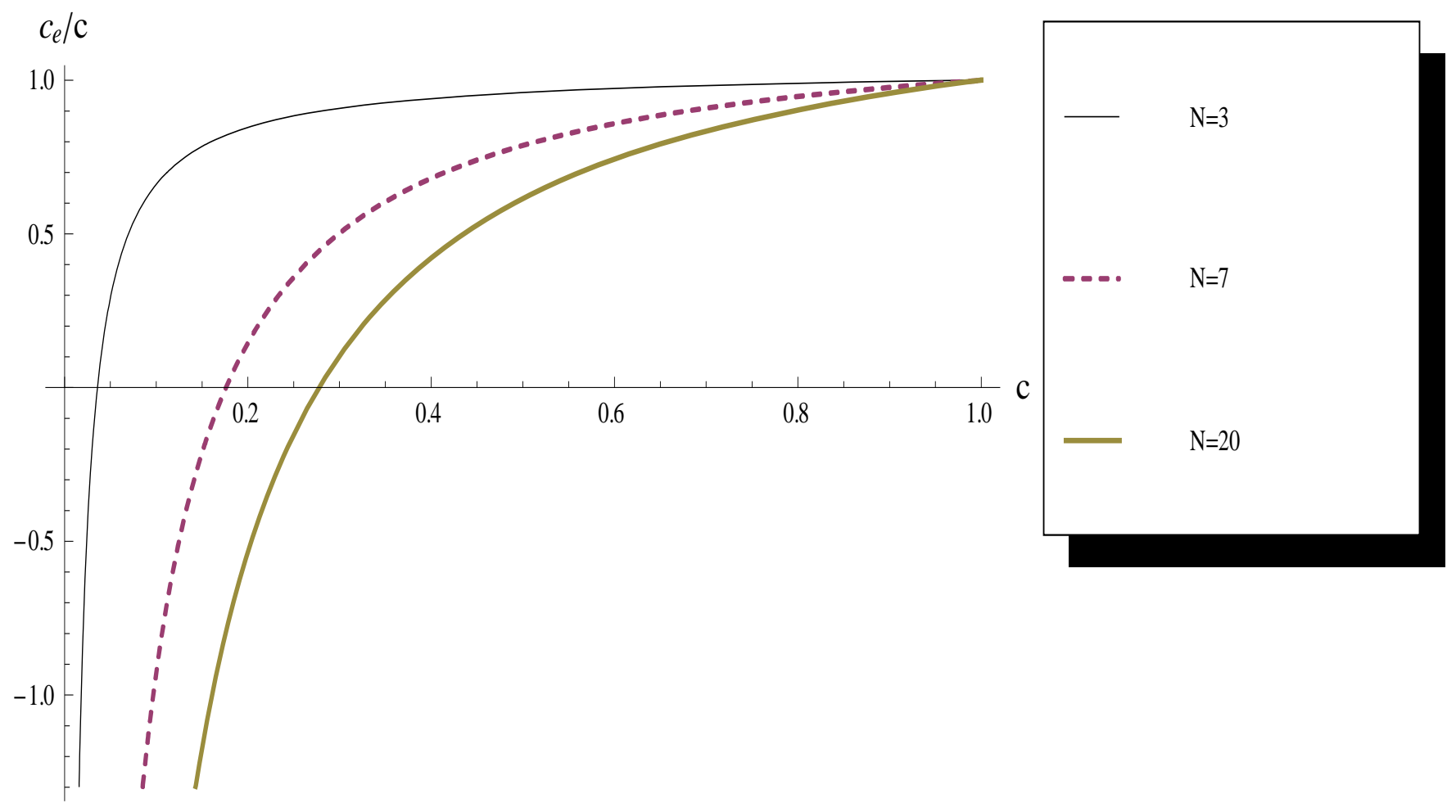

Figure 2

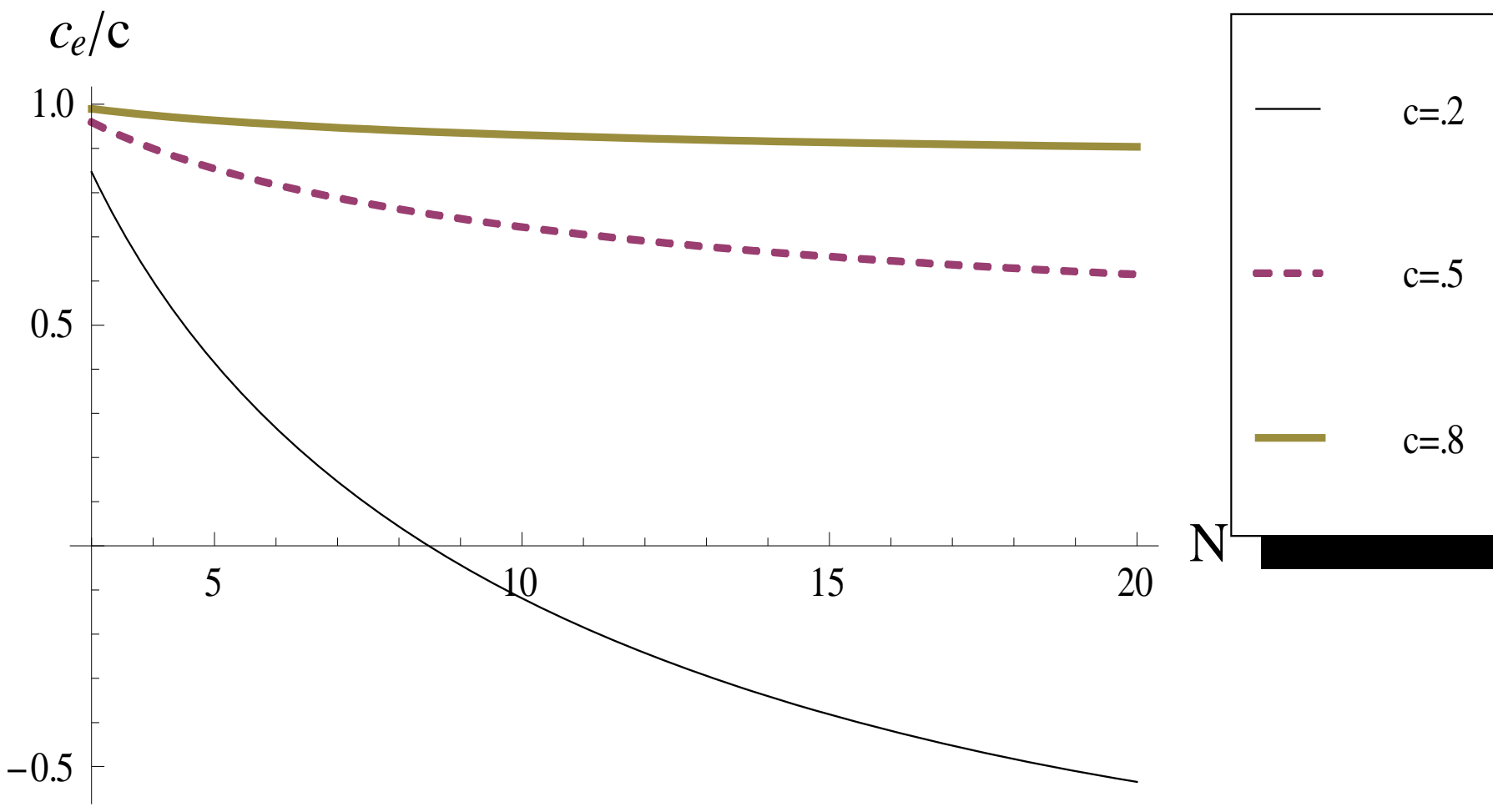


Figure 3: Optimal Discount--10\% Entrant Cost Advantage Optimal Discount

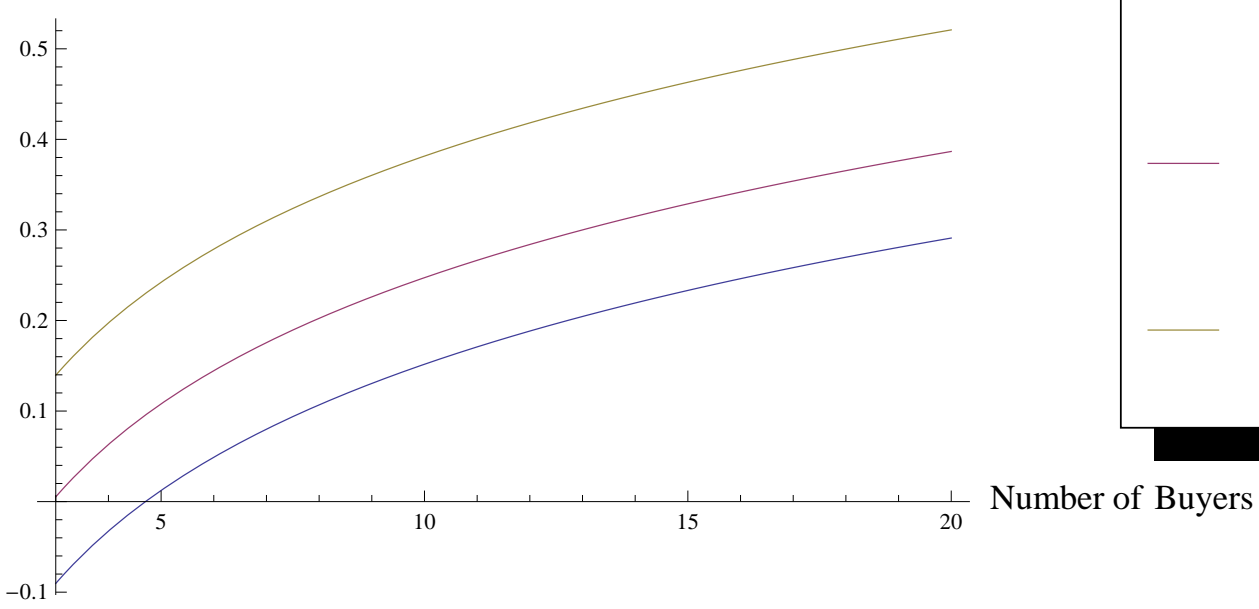

